\title{
Global LNG Pricing Terms and Revisions: An Empirical Analysis
}

\author{
Mark Agerton \\ Graduate Fellow
}

(C) 2015 by the James A. Baker III Institute for Public Policy of Rice University This material may be quoted or reproduced without prior permission, provided appropriate credit is given to the author and the James A. Baker III Institute for Public Policy.

Wherever feasible, papers are reviewed by outside experts before they are released. However, the research and views expressed in this paper are those of the individual researcher(s) and do not necessarily represent the views of the James A. Baker III Institute for Public Policy.

This paper is a work in progress and has not been submitted for editorial review. 


\title{
Global LNG Pricing Terms and Revisions: An Empirical Analysis*
}

\author{
Mark Agerton \\ Graduate Fellow in Energy Studies \\ James A. Baker III Institute for Public Policy \\ Department of Economics, Rice University \\ 6100 Main St MS-22, Houston, TX 77005 \\ magerton@rice.edu \\ (713) 348-3198
}

March 29, 2016

\begin{abstract}
Asian long-term contracts for liquefied natural gas (LNG) are generally thought to index LNG prices to oil prices. This should mean that LNG and oil prices are cointegrated. However, statistical evidence for cointegration using Japanese data is not strong. To resolve this puzzle, I examine 16 Japanese, South Korean, Taiwanese, and Spanish LNG import price series and allow for multiple, unknown structural breaks in the relationship to oil prices. This resolves the puzzle, and I provide estimates for the timing of breaks and the underlying average pricing terms. I relate these to count, volume, and duration data on long-term contracts and discuss how to interpret econometric estimates in light of contract data. This paper complements existing work on global gas market integration, which largely ignores how discrete changes in oil-indexed long-term contracts will affect empirical relationships.
\end{abstract}

Keywords. LNG prices, long-term contracts, structural breaks, cointegration

\section{Introduction}

It is commonly accepted that LNG prices have historically been indexed to crude oil benchmarks using slope-intercept pricing formulas, especially in Asia. This should result in strong statistical evidence of cointegration between oil and LNG prices. Engle and Granger (1987) and Johansen (1988) tests for cointegration confirm this for South Korean, Spanish, and Taiwanese prices: the

\footnotetext{
${ }^{*}$ Research support was provided by the Center for Energy Studies at Rice University's James A. Baker III Institute for Public Policy. I also thank Peter Hartley, Kenneth B. Medlock III, and Natalia Sizova at Rice University for their many insightful comments and suggestions, along with three anonymous referees. Special thanks to Weiran Yan, Wei Yang Tham, Ji Soo Kim, and Kate Kremling for their assistance. Thanks to Houston Stokes at the University of Illinois at Chicago for his assistance with a very early version of this paper. A previous version of this paper was presented at the 37th International Association of Energy Economics International Conference. Any errors are my own.
} 
null hypothesis of a spurious long-run relationship is strongly rejected by both tests at the $1 \%$ level for all of these series (see the last two columns of Table 1). However, such is not the case for Japan: the same tests do not suggest with a high degree of confidence that Japanese LNG prices are cointegrated with oil prices. The fact that LNG prices from the region's largest importer do not appear to have strong long-run links to oil is a puzzle given the commonly held view that Japanese LNG prices are oil-indexed. This paper shows how one can resolve this empirical puzzle by allowing for structural breaks in the LNG-oil relationship. Additionally, it uses data on longterm contracts to understand which estimates of the statistical relationship between LNG and oil prices are representative of actual contract terms and whether structural breaks are occurring due to changes in contract pricing terms or a country's portfolio of LNG contracts.

A long line of literature examining the convergence of global natural gas spot prices has indirectly approached this puzzle by measuring whether regional gas prices are cointegrated, which is a sign that markets are linked and arbitraged. Some recent papers on regional gas markets acknowledge that these markets are not well arbitraged. To model the degree and speed of gradual market convergence, these articles replace a cointegration framework with the Kalman filter ( $\mathrm{Li}$ et al. 2014; Neumann et al. 2006; Neumann and Cullmann 2012). Allowing for gradual integration seems appropriate for LNG markets because the majority of LNG has been traded under confidential, bilateral long-term contracts (LTCs) since the 1960s, not in a liquid spot market that responds rapidly to market conditions. In $201373 \%$ of all LNG trades took place under LTCs 11 Li et al. (2014) acknowledge this feature of the market and suggest that such contract revisions brought Japan into an Asian LNG price convergence club in the late 2000s. Convergence of prices in Asia, they conclude, may be more a result of a common oil indexation paradigm, not arbitrage in gas markets. At the same time, however, the modeling strategies in these papers ignore the fact that discrete changes in LTCs may produce discrete breaks in empirical relationships, not the smooth transitions captured by the Kalman filter.

There are a number of advantages to returning to a framework in which LNG and oil are cointegrated but with structural breaks in the relationship. First, if structural breaks are present, allowing for them ensures that parameter estimates are unbiased and that tests for cointegration do not erroneously suggest that LNG-oil relationships are spurious. Second, a cointegration framework explicitly captures LTC pricing terms. Estimates for 16 oil-LNG pricing relationships between different importer-exporter pairs in Japan, South Korea, Spain, and Taiwan shed light on these contracts' confidential pricing formulas and revision dates. Time series of LNG prices are not widely available, but public customs data can be used to generate average LNG prices at a more granular level than what has been considered in previous studies.

Before embarking on the main econometric analysis of LNG prices, I examine data on longterm contracts and the proportion of spot trades underlying each price series. This descriptive analysis demonstrates which importer-exporter prices should correspond to a single contract, and

\footnotetext{
${ }^{1}$ Author's calculations using data from the International Group of Liquefied Natural Gas Importers (GIIGNL) report "The LNG Industry 2013." GIIGNL classifies a short-term contract as one with a term of four years or less. In 2013, spot and short-term LNG made up $27 \%$ of the total trade, which means that LTCs made up $73 \%$.
} 
which series are generated by increasingly heterogeneous portfolios of contracts where portfolio changes, not pricing changes, induce empirical structural breaks. Econometric analysis shows that empirical LNG-oil relationships, which are likely to correspond to contract terms for several series, are far from uniform even within importing countries, and many appear to exhibit structural breaks. Nevertheless, most LNG prices appear strongly linked to oil, despite the initial lack of evidence for Japanese prices, which exhibit the most structural breaks in their relationship to oil. The higher number of breaks in Japanese series appears to have two causes. First, the number of contracts under which LNG is imported to Japan has generally increased and made LNG cargos more heterogeneous in terms of pricing. Second, Japanese contracts also appear to have undergone more revision than those signed by South Korean, Spanish, or Taiwanese companies. In particular, pricing terms appear to have increased as tight LNG markets during the mid-2000s caused a mismatch between the price of LNG determined by the upper tail of an S-curve and its value as a substitute for oil products. South Korean and Taiwanese LNG prices have generally been oil-indexed, and the relationships seem relatively stable. Spanish contracts also appear to be oilindexed, though less tightly and with a shallower slope term.

\section{Literature review}

\subsection{Theory: Long-term contracts in LNG}

Why LTCs? A well-known function of LTCs is to reduce the "hold-up" problem. LNG liquefaction and regasification terminals are enormous, irreversible investments. When there are limited buyers or sellers available to trade with (or only one), moral hazard may lead to underinvestment. This is because a buyer or seller fears that an opportunistic trading partner may try to renege on a deal once relationship-specific investments are made. Hartley (2015) models another rationale for LTCs in LNG markets cited by industry participants: LTCs stabilize cash flows and lead to reduced project financing costs. In the parlance of industry, these are "bankable contracts." ${ }^{2}$ Hartley finds that contracts are less beneficial when the average difference between the net-back prices received by exporters and the spot-market prices faced by the corresponding buyers - the rent which both parties split in an LTC - decreases. For example, hypothetical LTCs with Japanese buyers should be more valuable for new Malaysian projects as opposed to pre-existing projects in far-away Trinidad and Tobago.

Why an oil index? The use of an oil index to price natural gas in an LTC has sound economic rationale. In a thin market prices will tend to be volatile since small quantity shocks may represent a large share of total volumes. This presents a problem to any buyer or seller concerned with pricerisk. Tying LNG prices to a very liquid market is a way to reduce price volatility. Oil markets

\footnotetext{
${ }^{2}$ The importance of stabilizing cash flows forms the basis of predictions by Mitrova (2014) that Russia will continue to sell natural gas almost exclusively in long-term contracts with strong oil-indexation. Mitrova reasons that new gas supplies will be very expensive to develop, so securing buyers is necessary to finance the projects.
} 
are the natural pricing point for LNG since marginal buyers of natural gas - power plants - can substitute between gas and oil products in the short term to arbitrage price differences Hartley et al. 2007, 2008; Hartley and Medlock 2014). Over longer horizons substitution is also possible on the supply side and in other areas of demand, such as residential heating. Thus, the contractual linkage between LNG and oil prices is simply a reflection of an underlying economic relationship.

The future of LTCs A number of Asian buyers have begun to request that LNG prices be based not only on crude oil, but on other indexes as well, such as the Japan Korea Marker (JKM) spot price index published by Platts or the North American Henry Hub spot price index (Miyamoto \begin{tabular}{|l|l|l|l|l|l|l|}
\hline et al. 2009; Jensen 2011; & Ernst \& Young 2013; & Weems 2006; & True 2013; & Iwata 2012; & White 2014).
\end{tabular} It appears that recent North American LNG export contracts have already specified such pricing terms. Indexing LNG to non-oil benchmarks diversifies price risk and may allow Asian buyers to arbitrage regional price differences. Again, however, these updates to pricing formulas are simply the reflection of underlying arbitrage opportunities: just as power plants could switch between oil and gas, LNG buyers could source cargoes from regions with different prices.

Contracts appear to be getting more flexible as well, which is consistent with theoretical models. Hartley (2015) finds that deeper spot markets incentivize firms to increase contract flexibility and the share of spot purchases. Ikonnikova et al. (2009) come to a similar conclusion that spot market liquidity and demand uncertainty result in more flexible contracts and spot trading. Brito and Hartley (2007) provide yet another rationale for LTCs: if spot markets are thin, buyers and sellers may incur costly delays as they wait for a suitable spot-trading partner. The corollary to these papers is that the historical lack of liquidity in LNG spot markets contributed to the dominance of long-term contracts.

From theory to data The econometric analysis I perform confirms the ideas above. First, I verify that many LNG prices have indeed been indexed to oil, albeit with structural breaks. Though the theoretical literature has ignored the role of revisions to pricing terms in LTCs, such revisions can induce breaks that cause simple cointegration analyses to reject oil-indexation. Second, the fit of the econometric model estimated is not as tight in recent years for some of the series analyzed. This could well correspond to the increasing heterogeneity of pricing terms for LNG cargoes that make up the customs data I use in the analysis.

\subsection{Empirics: Cointegration and LNG prices}

Many of the cointegration analyses of oil and natural gas prices have come from a literature that examines the convergence of regional spot markets to a single market. The presence of cointegration reveals that traders can arbitrage price differences between two markets. This paradigm is different from one dominated by long-term contracts. While the former structure is characterized by arbitrage in the relatively short run, the latter may be characterized by infrequent and discrete changes to pricing regimes that are determined through bilateral negotiations. The two market 
structures should generate distinct time series, and tools to analyze the former may not be suited to the latter.

De Vany and Walls (1993) pioneered the literature on gas market integration. The authors use cointegration analysis to show how unbundling pipeline ownership and capacity rights increased integration of regional spot prices in the United States. More recently, Siliverstovs et al. (2005) use the Johansen test for cointegration to investigate relationships between European, Japanese, and North American gas prices. The authors find that European and Japanese gas prices are cointegrated but reject an absolute version of the law of one price, which would require that percent changes in European gas prices and Japanese LNG prices be one-for-one. The authors also reject the hypothesis that North American prices are cointegrated with prices in Europe or Asia. Neither paper considers structural change or distinguishes between pairs of trading partners. In Neumann et al. (2006) and Neumann and Cullmann (2012), the authors relax the assumption of a stable empirical pricing relationship, but remain within the framework of a spot-market. Using a timevarying Kalman filter, they show that European gas markets have become more tightly integrated over time. This technique does not characterize discrete structural breaks that could result from contract revisions as mine does; instead, it tends to characterize smooth changes.

Li et al. (2014) extend Neumann et al. (2006) and Neumann and Cullmann (2012) by using tests for statistical convergence among multiple series to examine the convergence of gas prices between 1997 and 2011. They examine prices in South Korea, Taiwan, Japan, North America, and the United Kingdom (U.K.), and they conclude that Asian and European gas markets are integrated because of contractual links to oil prices, not arbitrage in a spot market. In addition to employing a different econometric methodology, I also use unfiltered, less aggregated data, which does not obscure discrete changes in the oil-LNG relationship. This allows estimation of actual pricing terms for some series. Li et al. (2014) do find some evidence that Japanese prices join a South Korea-Taiwan "convergence club," though only more recently, and they suggest that the later entry of Japan is due to lags in LTC revisions. Along with Miyamoto et al. (2009), I provide further explanation for the authors' finding. The use of S-curve pricing (see Figure 2) in several Japanese LTCs meant that some Japanese LNG prices were determined by the upper tails of S-curves during the mid-to-late 2000s. During this time Japanese prices were significantly discounted in relation to those in South Korea and Taiwan as well as the oil market. In 2008-2009, it appears that some Japanese S-curve provisions may have been eliminated, and prices regained rough thermal parity with oil.

This paper complements the literature on global gas market-integration. These papers tend to focus on the cross-country relationships between gas prices while ignoring the underlying contract terms that set prices. I take oil-indexation terms of LTCs seriously as the data-generating process but ignore the statistical relationships between gas prices in different countries. Empirically, my paper is closest to Ramberg and Parsons (2012) and Brigida (2014), who estimate cointetgrating relationships between North American oil and gas prices allowing for a single break and switching between two regimes, respectively. Unless multiple regimes are allowed, evidence for the cointegra- 
tion of oil and LNG prices is mixed, but once breaks are allowed, these tests support the expected strong long-run link. The data, market structures, and interpretation of structural changes in this paper are different from Ramberg and Parsons (2012) and Brigida (2014), but the spirit is similar.

\section{$3 \quad$ Why expect structural breaks?}

There are three reasons to expect structural breaks in empirical LNG-oil pricing relationships. First, pricing terms in LTCs are renegotiated periodically. Second, nonlinear pricing formulas may cause breaks in linear relationships. Third, LNG prices calculated from the customs data I use are averages over individual cargoes, so as the mix of contracts under which cargoes are imported changes, empirical relationships may change.

Renegotiation clauses Despite the fact that LNG pricing terms are closely guarded commercial secrets, it is generally accepted that contracted LNG prices (particularly in Asia) are indexed to crude oil with a slope-intercept formula such as

$$
P_{L N G}=a+b \times P_{O i l} .
$$

As explained earlier, such pricing relationships are based on the underlying substitution possibilities between oil and natural gas. Pricing terms, however, may be revised as market fundamentals cause the value of LNG (for example, the spot price) to diverge from the price specified in an LTC. Revisions to pricing formulas will alter the underlying data-generating process and result in a structural break in the empirical relationship. Such a situation could easily arise as supply and demand shift or new substitution possibilities arise through technological innovation, geographical availability of supply and demand, or other factors.

In a review of more than 40 years of LNG contracts, Weems (2006) briefly describes clauses that specify when and how re-negotiations occur. He quotes one contract from the 1980s with a representative renegotiation clause, which states that parties will regularly re-evaluate the contract "in good faith in the light of all the circumstances relevant at the time." In a paper three years later, Miyamoto et al. (2009) identifies 2004 as a time when changes in market fundamentals altered the relative prices of LNG inside and outside of Japanese contracts, triggering changes in pricing formulas:

In 2004 . . . delays to new projects and spikes in demand caused the international LNG market to begin to tighten, transforming it into an out-and-out seller's market. Consequently, this period saw moves to drastically raise LNG prices in the high crude oil price range, such as by abolishing the S-curve method and adopting a straight-line formula, and by increasing the slope of [the] pricing formula.

Miyamoto's observations about market conditions are easily visualized. Figure 1 shows how 
Figure 1: Actual vs short vs long-term LNG volumes by region

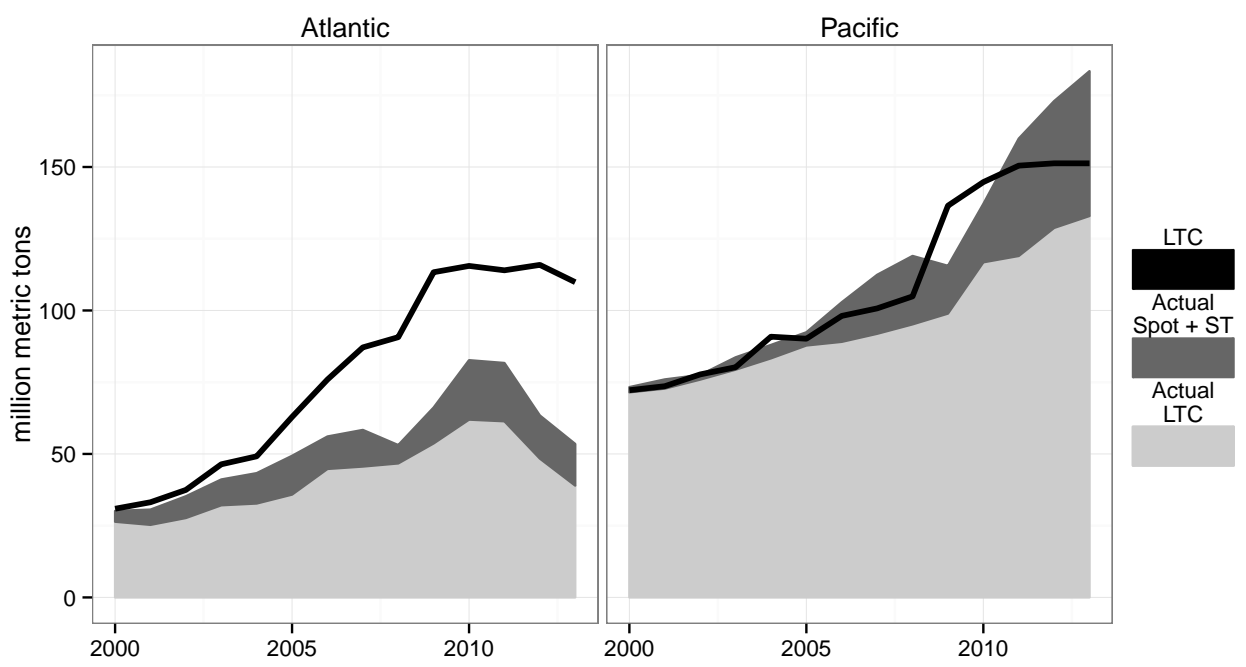

Source: GIIGNL and author's calculations

LNG imports to countries in the Atlantic and Pacific basins $3^{3}$ over the past 14 years have followed different patterns that are indicative of large changes in market fundamentals particular to each region. The plot shows data from International Group of Liquefied Natural Gas Importers (GIIGNL) reports for 2000-2013 and breaks out three quantities. First, the black line shows the volumes specified under LTCs (defined as contracts with a duration of more than four years). Second, the dark gray area shows the volumes imported under short-term or spot contracts (defined as contracts which have a term of four years or less) 4 Third, the light gray area shows the actual volumes imported under LTCs (defined as contracts with a term of more than four years).

In 2011, the Fukushima nuclear disaster in Japan resulted in the shut-down of all nuclear power plants in the country as well as an increase in LNG demand by gas-fired electricity generators who filled the gap. Figure 1 shows that spot volumes in the Pacific rose sharply that year, and total volumes substantially exceeded LTC commitments. In the Atlantic basin, however, total imports of all kinds have been less than the volumes committed under LTCs. Since the mid-2000s, the United States has experienced large increases in natural gas production from shale; this was not expected when long-term deals would have been inked. As production of natural gas increased in North America and depressed prices, expensive LNG imports were not economical. One might infer that these long-term contracted volumes may have been diverted to other buyers. It is not clear $a$ priori how (and whether) such shifts in market fundamentals translated into LTC revisions, but it is plausible that they did affect pricing.

\footnotetext{
${ }^{3}$ The United States, Mexico, and countries on the Mediterranean Sea are classified as Atlantic importers. Gulf Coast countries are classified as Pacific importers.

${ }^{4}$ GIIGNL provides two figures: actual total trade volumes of any type and actual trades under spot or short-term contracts. I subtract the former from the latter to obtain actual LTC volumes.
} 
Figure 2: Hypothetical S-curve for U.S. LNG exports

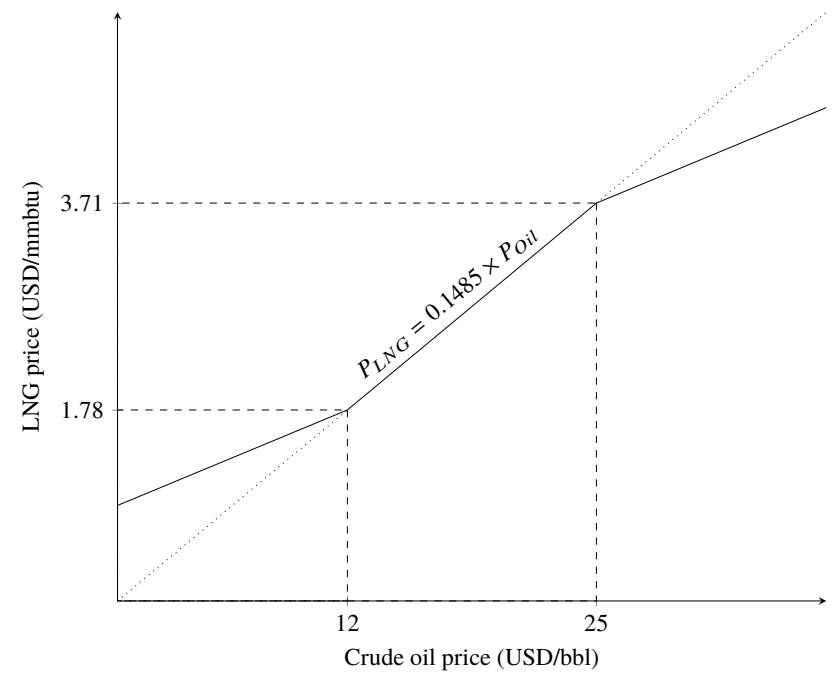

S-curves Another reason the empirical relationship between crude oil and LNG prices may exhibit structural changes is that a number of Asian LNG contracts have specified "S-curve" pricing formulas. Such formulas dampen the impact of very high or low oil prices on LNG prices (see Figure 2) $5^{5}$ The presence of an S-curve implies that the slope of the relationship between oil and natural gas prices changes and becomes shallower as oil prices move into an upper or lower range. Though the use of an S-curve is not a change in the underlying data-generating process per-se, it could well appear as a break in the parameters of a linear relationship, especially since oil prices began moving higher in 2004 and did not fall back to their previous levels over the time considered. If a kink is specified at $\$ 24 / \mathrm{bbl}$ oil-as Flower (2011) claims is the case for Japan-Qatar contracts - identifying whether a break occurs in the time dimension or price dimension would not be possible with the data at hand. Both Weems (2006) and Miyamoto (2008) document the use of S-curve pricing formulas from the 1980s through the mid-2000s, and filings in 1994 and 1999 related to Alaskan LNG exports to Japan explicitly mention such S-curve behavior, with kinks falling at $\$ 11$ or $\$ 13 / \mathrm{bbl}$ oil prices for the lower tail and $\$ 25$ or $\$ 26 /$ bbl for the upper tail (see Section 6.1 for further discussion of the Alaskan contracts).

Heterogeneity in contracts A final reason breaks in the empirical LNG-oil price relationship may occur is that for a given importer-exporter pair, there can be multiple contracts under which LNG is imported. This is more a feature of the customs data I use than the contracts themselves. Particularly in Japan, many companies import LNG from the same country of origin under separate agreements . Additionally, the share of spot and short-term imports - which may be priced differently than volumes purchased under LTCs - has increased substantially over the past decade. In 2000, spot and short-term volumes made up just over $5 \%$ of the global LNG trade; in 2013,

\footnotetext{
${ }^{5}$ An S-curve could also reflect underlying economic relationships. As oil prices rise or fall, some decisions may be on a corner, and substitutability between the fuels could decline.
} 
they were $27 \%$ (recall Figure 1). As the mix of agreements under which LNG is imported changes over time, it is reasonable to expect changes in empirical relationships between crude benchmarks and average LNG import prices: coefficients may shift, model fit may worsen, and the estimated variance of the error process may increase. The possibility of underlying heterogeneity in the LNG cargos that make up customs data does make interpreting estimated parameters and break-dates as actual pricing revisions problematic for several series. Nevertheless, a number of trade-routes have only one or two contracts listed in GIIGNL reports and little or no spot trade since 2000 (for example, Japan-Brunei). For these series, it is reasonable to interpret parameters and structural breaks as corresponding to actual pricing terms and revisions. Section 5 discusses the mix of LNG contracts corresponding to each price series and the implications for interpreting estimates.

\section{Data}

LNG Prices LNG prices are constructed using country-level customs data on the quantity and value of imports from a particular exporter 6 I compute average prices by dividing the total weight of LNG imports by their monetary value, and I convert the per-ton price to a per-MMBtu basis.7 Currency conversions are required for Japan, Taiwan, and Spain. Monthly averages of weekday exchange-rates from the Federal Reserve "Foreign Exchange Rates" tables were used to convert foreign currencies to U.S. dollars 8 Japan's dataset is the longest, stretching back to 1988. South Korea's customs data begin in 1995; Taiwan's, in 2000, and Spain's, in 1995. Japanese and South Korean pricing relationships were estimated with data through June 2014, while Spanish and Taiwanese relationships were estimated with data through May 2014. Some LNG trade-routes contain months with no trade and, therefore, no prices. In these cases, I use the largest contiguous series of prices, eliminating initial or final months for a few cases.

Summary statistics are in Table1. The table includes Dickey-Fuller tests for the null hypothesis of a unit root. A unit root cannot be rejected at the $10 \%$ level for any series, so cointegration is an appropriate framework $!^{9}$

\footnotetext{
${ }^{6}$ While data are available at the port-level for Japan and Spain, I elect not to use a panel approach and simply aggregate to the national level. Many ports have missing months, and scatter-plots of the data are qualitatively very similar to those in Figures $8 \mathrm{a}$ and $8 \mathrm{~b}$

${ }^{7}$ An approximate conversion is $51.813 \mathrm{MMBtu} /$ metric ton. There are approximately $5.8 \mathrm{MMBtu}$ per barrel of crude oil. While GIIGNL reports that list average LNG characteristics show that different liquefaction plants have different calorific contents, this data is unavailable before 2003 and may not correspond to what is traded under LTCs. In fact, the tables are for "non-contractual" characteristics.

${ }^{8}$ Historical data from the U.S. Federal Reserve was used for the pre-Euro European Union basket of currencies.

9 Perron (1989) showed that if structural breaks and trends are allowed, one can reject the null hypothesis of a unit root. A robust debate about the stationarity of oil prices has ensued, and both Noguera (2013) and Ghoshray (2014) confirm that one can reject the unit root hypothesis if structural breaks, time trends and nonstationary volatility are allowed in oil prices. In fact, a Zivot and Andrews (1992) test allowing for a single break in intercept and trend rejects a unit root at the 1 or $5 \%$ level for 10 of 16 series, plus Brent and JCC. The unit root properties of LNG and oil prices, however, are not the central focus of this paper, and to stay consistent with the extensive literature on the empirical oil-gas price relationship, I maintain a cointegration framework in which both variables have unit roots (Villar and Joutz 2006, Brown and Yücel 2008, 2009, Hartley et al. 2008 Ramberg and Parsons 2012, Hartley and Medlock 2014: Brigida 2014). Furthermore, Bai and Perron (1998) and Kejriwal and Perron (2008b) show that the sup Wald test will consistently detect breaks whether regressors are stationary, trend-stationary or difference-
} 
Crude oil prices There are two logical choices for a crude oil benchmark: Brent crude and Japanese Crude Cocktail (JCC) 10 The first is available beginning in 1984, and the second, January 1988. Brent is a light, sweet and primarily waterborne crude oil from the North Sea, and it is the most commonly referenced global crude oil benchmark. JCC is a weighted average price of crude oil imports to Japan. It is generally thought to be the benchmark used in Asian pricing formulas. Monthly Brent crude prices were gathered from the U.S. Energy Information Agency (EIA). I construct my own JCC from customs data since the official one from the Petroleum Association of Japan (also based on customs data) is only available beginning in $2000{ }^{11}$

\section{Analysis of long-term contracts}

Figure 3 shows total import volumes for Japan, South Korea, Taiwan, and Spain from 1964 to 2013. Figure 4 breaks out 2000-2013 import volumes associated with the 16 price series I analyze. The 16 series correspond to a large share of global LNG imports, which means that econometric results should be representative of broad market tendencies.

As stated previously, interpreting empirical estimates as actual contract parameters and revision dates is problematic for some series given the confidential nature of contracts. However, GIIGNL data show that some of the aggregate series are associated with only one contract, or have a homogeneous composition throughout all or much of the time considered. To get a sense of how many contracts are associated with customs data for each trade-route, I compiled the list of the LTCs in force from 2000 to 2014 (see Table 2). Over that period, the number of contracts generally increased for each trade route. The data on spot and short-term imports show a similar pattern: spot trades were only $5 \%$ of global trade in 2000, but were substantial by 2013 (see Figure 1 for the Atlantic and Pacific aggregates and Figures 5 and 6 for importer-exporter pairs). Given the increasing trends in both the number of contracts and shares of spot trades, I assume that there were fewer LTCs and minimal spot trades prior to 2000 for the series I consider.

Series most likely to reveal actual prices Table 2 shows that five of the 16 series had only one long-term contract for the 2000-2013 period: Japanese imports from the United Arab Emi-

stationary, and the BIC and LWZ criterion remain valid indicators of the correct number of breakpoints, though the tests' distributions may change. The fact that estimated breakpoints are generally consistent with these statistics should mitigate concerns about the unit root properties of each series.

${ }^{10}$ According to Miyamoto et al. (2009), the Japan-Indonesia contract uses the government-reported Indonesian Crude Price (ICP), which is not available publicly.

${ }^{11} \mathrm{My}$ series is a weighted average price of all crude oil imports into Japan. The relevant imports are designated by Harmonized System (HS) codes beginning with the digits 2709. I convert from Yen/kL to USD/bbl using official volume-to-weight conversions from the Petroleum Association of Japan and foreign exchange rates from the Federal Reserve. The series is quite close to the official Petroleum Association of Japan one, and differences primarily appear to be due to the use of different foreign exchange rate indexes. 
Figure 3: Historical LNG imports

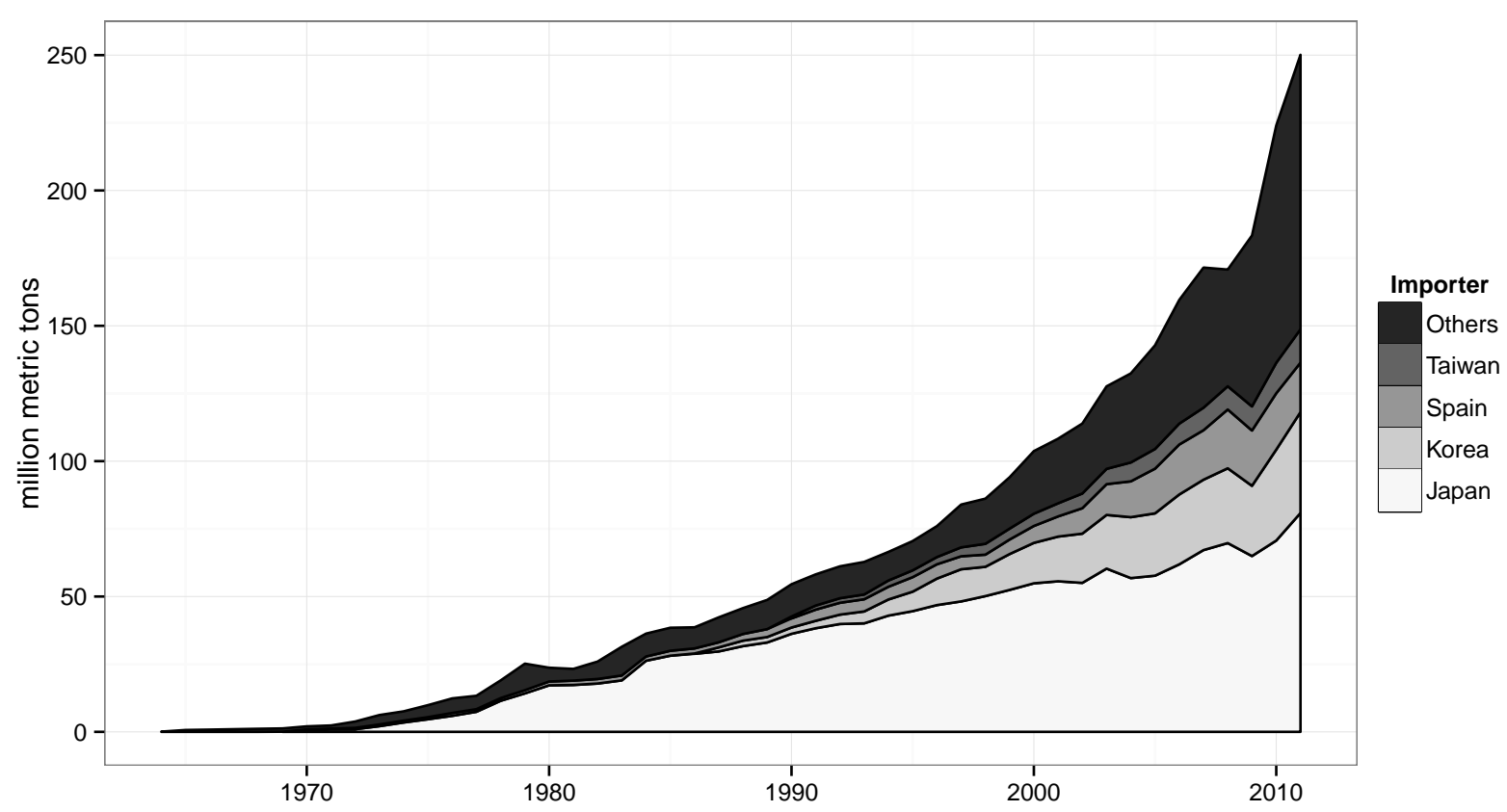

Source: Petroleum Economist and author's calculations

rates (U.A.E.) ${ }^{12}$ Brunei ${ }^{13}$ and the United States ${ }^{14}$, Korean imports from Oman ${ }^{15}$; and Taiwanese imports from Malaysid 16 . Given that LNG volumes have steadily increased over time, I take this as an indication that there was at most one contract in effect prior to 2000 for each of these series. Furthermore, spot and short-term volumes for the first three trades were less than $13 \%$ of total trade as long as LTCs were in force (U.S. imports switched to short-term contracts in 2009), and Brunei cargoes were less than 5\% spot or short-term until 2013. Omani cargoes to South Korea were composed of up to $24 \%$ spot volumes in 2006 , but only one buyer and one seller were involved in the trade. Similarly, Malaysian spot exports to Taiwan were 8-16\% from 2005 to 2008, but minimal otherwise. Australian LNG appears to have been imported to Japan under a single contract until $2003{ }^{17}$ With negligible spot imports from Australia before 2003, it is safe to assume that 14 years

\footnotetext{
${ }^{12}$ Abu Dhabi Gas (ADGAS) signed a 20 year LTC with Tokyo Electric Power Company (TEPCO) in the 1970s to export LNG from its first two trains, and a new deal in 1990 to double volumes using the third train. This is consistent with customs data. http://www.adgas . com/En/SitePages/About\%20Us/Chronology.aspx

${ }^{13}$ Customs data show flat volumes from Brunei since 1988, which corresponds to the contract listed in GIIGNL reports.

${ }^{14}$ The contract recorded in GIIGNL data, which begins in 1989, was between Phillips and Marathon in the United States and TEPCO and Tokyo Gas in Japan. It was extended for five years in 2004 and expired in 2009.

${ }^{15}$ The single contract specified in GIIGNL began in 2000 and specified 2 mtpy from 2000 to 2001. Volumes increased to 4 mtpy thereafter.

${ }^{16}$ There was a single contract from 1999-2014 for $2.25 \mathrm{mtpy}$.

${ }^{17}$ According to customs data, Japanese import volumes of Australian LNG began in 1989, ramped up steadily until 1995 as new trains came online at the Northwest Shelf LNG plant and stayed relatively flat through 2003. GIIGNL data, available starting in 2000, show only one LTC between Japanese companies and Australia through
} 
Figure 4: LNG import volumes (mtpa) associated with series analyzed
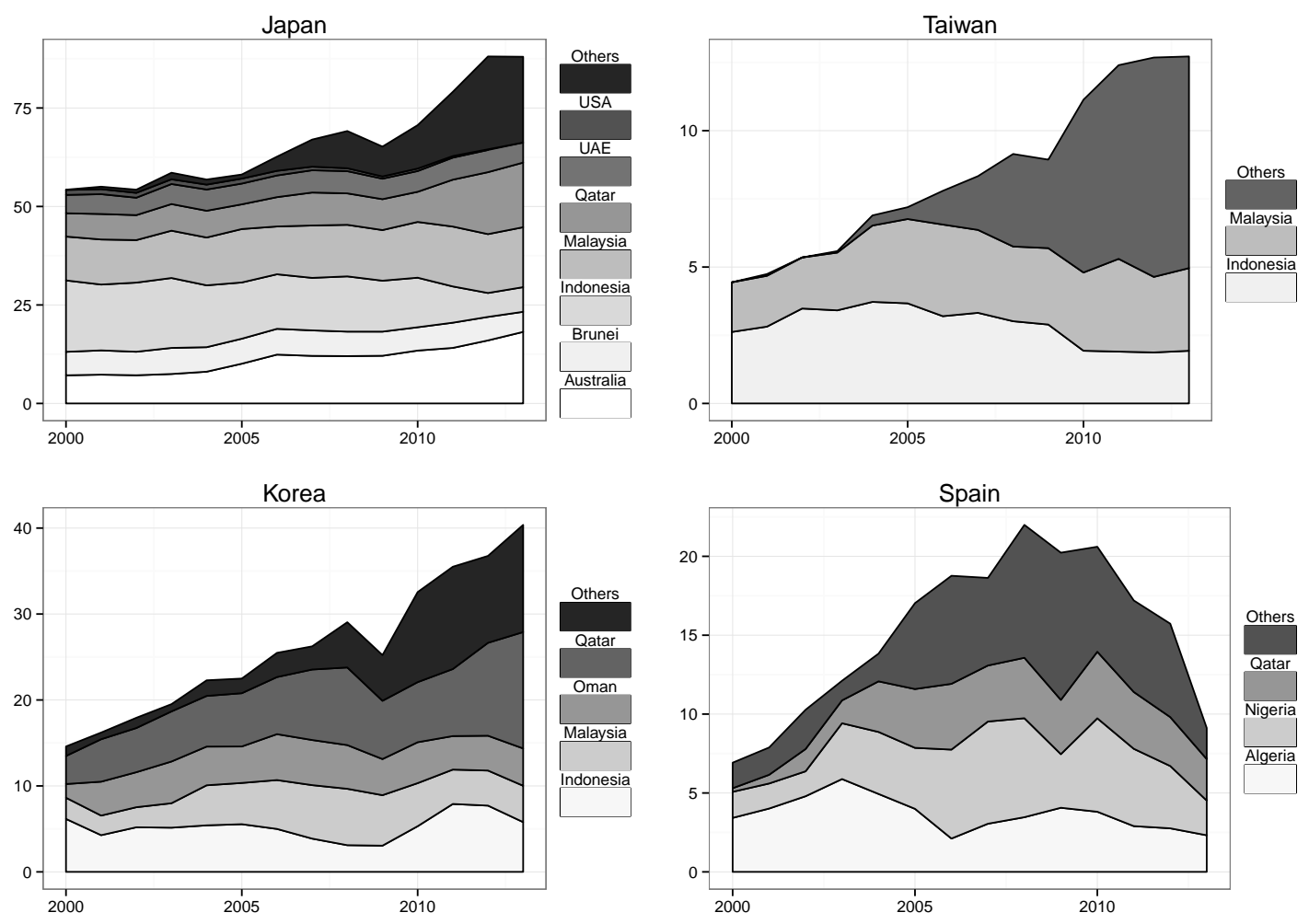

Source: GIIGNL and author's calculations 
Figure 5: Japan: Actual, spot and contracted imports by exporter

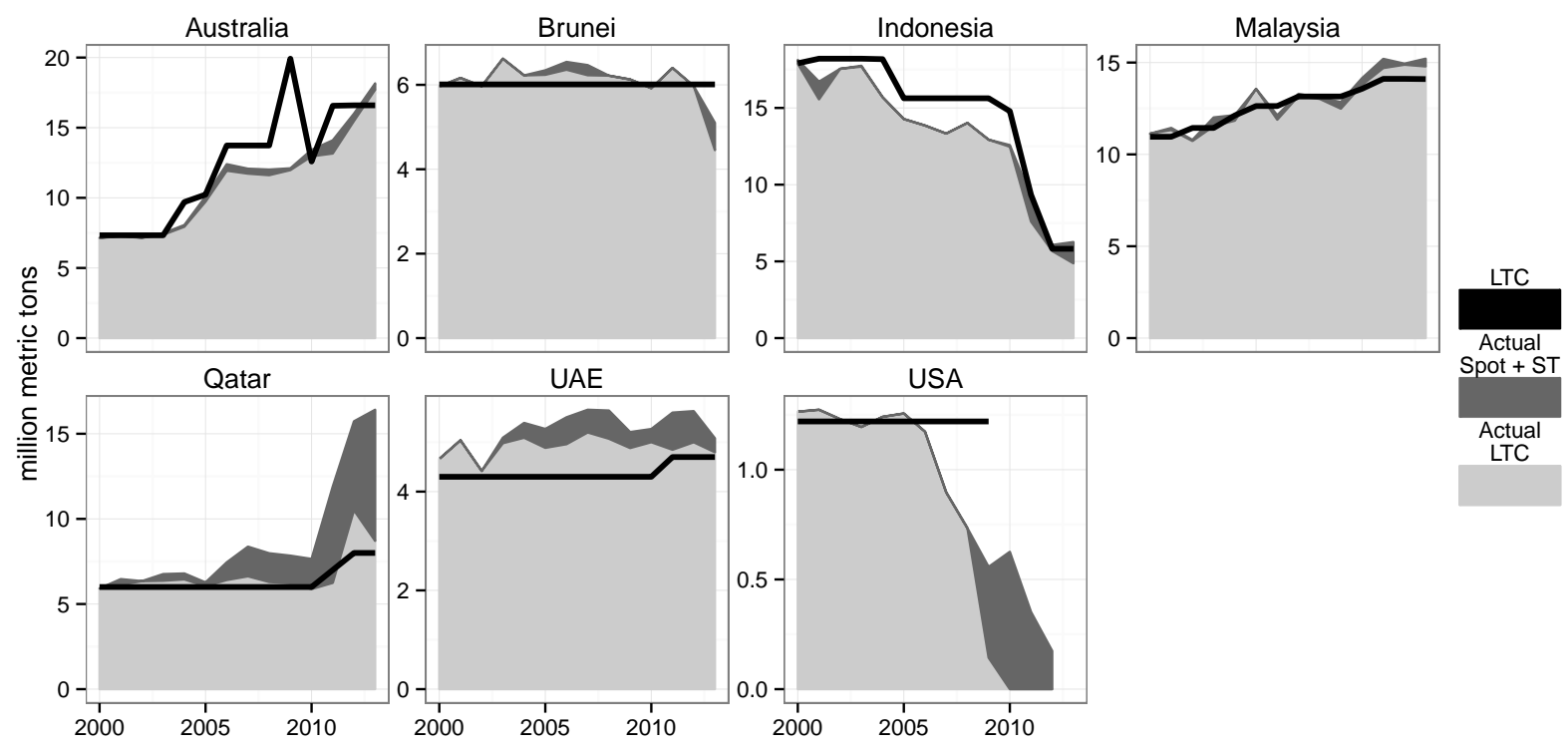

Source: GIIGNL and author's calculations

of average import prices correspond to a single LTC. Given the relative homogeneity implied by a single LTC and relatively lower spot imports, we can reasonably assume that time-series estimates reflect underlying contract parameters for these series.

Series that allow for more insight into contracts A few other LNG price series are generated by a single set of very few LTCs. While pricing formula estimates for these series will, naturally, be averages, breaks should be apparent when pricing terms change substantially. For Japan, there were only two Qatari LTCs with Japanese companies from 2000 to 2010, and spot imports only rose above $10 \%$ starting in 2006 . This provides a period of relative homogeneity during which we can interpret parameters as average pricing formulas and empirical breaks as contract revisions. Similarly, LNG volumes to Taiwan from Indonesia were steady from 2001 to 2010 under the same two contracts with no spot imports during this time.

Cargo composition changes and breaks Large changes in the makeup of LNG cargoes may lead to structural breaks. For example, almost half of the contracted volumes for the IndonesiaTaiwan trade discussed in the previous section expired in 2010. Similar changes happened with Japanese imports from Australia, Qatar, and Indonesia. When the 1989 Japan-Australia LTC expired in 2009, the contract represented more than $50 \%$ of LNG trade between the two countries. The number of LTCs, which had steadily climbed to seven from 2003 to 2009, leapt to 17. Qatari

2003. Since this contract began in 1989 when production from the first train started up, I assume that there was only one Australian LTC for Japan from 1989 to 2003. 
Figure 6: S. Korea, Taiwan, and Spain: Actual, spot and contracted imports by exporter
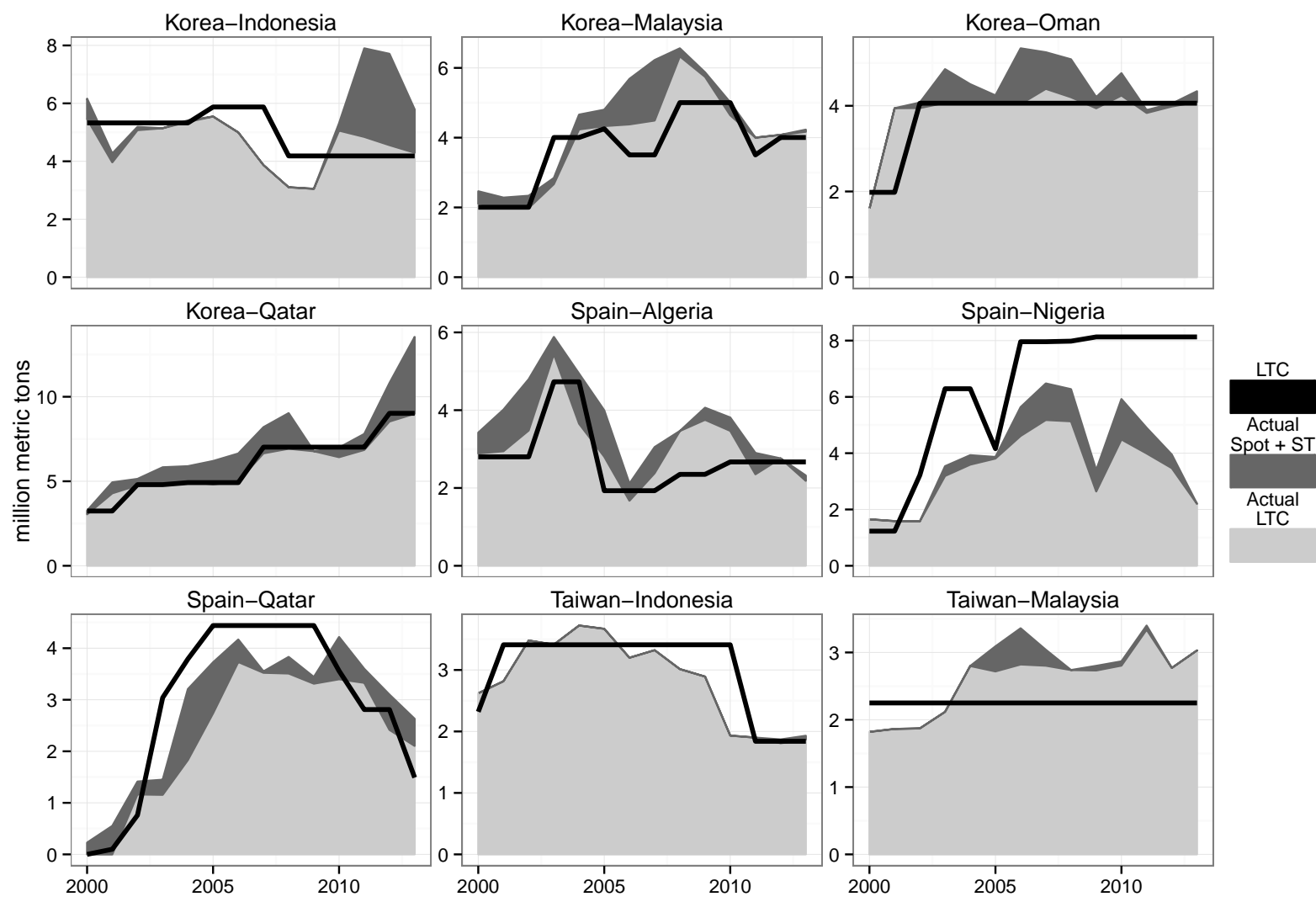

Source: GIIGNL and author's calculations

volumes were initially sold to Japan under just two agreements that began in 1997 and 1998. No additional agreements were signed until 2011 (when the Fukushima disaster occurred), and spot volumes were below 15\% until 2007. For both Australian and Qatari average LNG prices in Japan, one can expect that the statistical relationship with oil prices weakened after 2003 and 2007, respectively, due to increased heterogeneity in LTCs. Indonesian cargoes to Japan were imported under five LTCs until 2011, and the share of each did not change during this time ${ }^{18}$ In 2011 , the first Japan-Indonesia LTC, which represented more than $50 \%$ of the trade, expired, causing total volumes to plummet and the share of spot and short-term imports (negligible until that time) to spike to $17 \%$.

Heterogeneity in contracts Other series have substantial - and often increasing - heterogeneity in their makeup. The volume and number of Malaysian LTCs with Japanese companies steadily increased between 2000 and 2013 (though spot sales did not). Similarly, spot and short-term sales

\footnotetext{
${ }^{18}$ The first three LTCs, signed before 1988 when my data begin, represented 15 out of 18 mtpa in contracted volumes. A contract for 2.3 mpta began in 1994, and two LTCs for less than 0.5 mtpa were signed in 1996 and 2000.
} 
from Malaysia and Oman to South Korea were substantial. The set of importing contracts to Spain from Algeria, Nigeria, and Qatar steadily increased in complexity from 2000 to 2013. In fact, Nigerian contracts began incorporating destination flexibility in later years, so volumes could have been directed to Spain, the United States, or Mexico. Clearly, interpreting estimates as actual pricing formulas or as hard evidence of contract revisions with these series is not possible unless an extremely tight model fit suggests otherwise.

\section{Empirical approach and estimation}

I explicitly base my statistical model on actual pricing formulas as described in legal documents filed with the U.S. Federal Energy Regulatory Commission (FERC) — not rules of thumb or purely theoretical models. The FERC provides copies of three amendments and approvals (in 1988, 1991 and 2000) to the long-term LNG sales and purchase agreement under which Phillips and Marathon exported LNG from Kenai, Alaska to the Tokyo Electric Power Company (TEPCO) and the Tokyo Gas Company in Japan 19 These documents list three different pricing regimes. Each requires a "redetermination of the contract price" when the base crude index (JCC, in this case) is outside of the range $\$ 13-26 /$ bbl (1994) and subsequently $\$ 11-25 /$ bbl (1999). Such "redetermination" is consistent with S-curve behavior, and the kink-points are close to those specified in Qatar-Japan contracts as described by Flower (2011). Documents describing the pricing terms of Alaskan LNG exports all explicitly state that LNG is priced to be competitive with both crude oil as well as LNG from other countries. This suggests that the functional form of the Japan-United States pricing formula is similar to those in other contracts.

Based on the language describing LNG pricing terms, there are two features a statistical model should take into account. First, LNG can be indexed to an average of past monthly oil prices, not the contemporaneous one. I account for the averaging of prior monthly prices by adding lagged differences of oil prices in the econometric model. Since my specification is a one-to-one transformation of the U.S. pricing formula, it is simple to recover implied pricing terms. Second, empirical LNG pricing relationships may have structural breaks that are unknown in number and position but must be estimated. The structural break estimation technique I use chooses the locations of a given number of structural breaks to minimize the sum of squared residuals (SSR). Each time an additional break is permitted, if the improvement in fit (after accounting for serial correlation) is not statistically significant, one accepts the null hypothesis that no additional breaks are present. It is critical that a certain percent of the observations lie between breaks, so breaks cannot be too close together, or too numerous. Bai and Perron (1998) and Kejriwal and Perron (2008b) show that the technique can be employed with stationary, trending, or cointegrated variables. Though critical values change with the univariate stationarity properties of the regressors, the appropriate information criterion do not. Readers not interested in econometric details can skip to Section 7 .

\footnotetext{
${ }^{19}$ Available at http://www.fossil.energy.gov/programs/gasregulation/authorizations/Authorizations. html
} 


\subsection{Econometric pricing formula}

Slope-intercept LNG pricing formulas that change over time can be expressed as

$$
y_{t}=c_{j}+\delta_{j} \tilde{z}_{t}+u_{t} \quad t=T_{j-1}+1, \ldots, T_{j}
$$

where $y_{t}$ is the LNG price, $z_{t}$ is the oil price, and $\tilde{z}_{t}=\sum_{r=0}^{p+1} \theta_{r} z_{t-r}$ is the benchmark oil price, which is a weighted average of present and past oil prices. Weights are $\theta_{r} \in[0,1]$ and sum to one. Time is indexed by $t$ with breakpoints at times $T_{j}$. The first period in a regime $j$ is $T_{j-1}+1$, and the last, $T_{j}$. There are $j=1, \ldots, m$ breaks and $m+1$ regimes. The start of the series is $T_{0}=0$, and the endpoint is $T_{m+1}=T$. The number of breakpoints $(m)$ and their locations $\left(\left\{T_{j}\right\}_{j=1}^{m}\right)$ are unknown, and I wish to estimate them along with the intercepts $\left(c_{j}\right)$, slopes $\left(\delta_{j}\right)$, and oil-price weights $\left(\theta_{r j}\right)$ for each regime $j$. LNG and oil prices ( $y_{t}$ and $z_{t}$, respectively) have unit roots, and $u_{t}$ is a stationary, mean-zero error process with possible serial correlation.

Equation (1), which bases LNG prices on a weighted average of past oil prices, can be easily transformed ${ }^{20}$ into a unique Dynamic OLS (DOLS) model (regime subscripts $j$ are omitted for simplicity):

$$
y_{t}=c+\delta z_{t}+\sum_{s=0}^{p} \pi_{s} \Delta z_{t-s}+u_{t}
$$

where coefficients on differences of $z_{t}$ are $\pi_{s}=-\delta \sum_{r=s+1}^{p+1} \theta_{r}$. The original weights can be recovered 21 as

$$
\theta_{0}=1+\pi_{0} / \delta \quad \theta_{p+1}=-\pi_{p} / \delta \quad \theta_{r=1, \ldots, p}=\left(\pi_{r}-\pi_{r-1}\right) / \delta .
$$

A DOLS model is preferable to an Autoregressive Distributed Lag (ADL) model or other candidates for three reasons. First, the most interesting parameter is the slope in the cointegrating relationship $(\delta)$. By including only one level of oil prices, I avoid high collinearity between lagged levels and can obtain more precision in my estimates of the slope. Second, asymptotic theory has been developed for the DOLS model with endogenous structural breaks. The distribution of breaks is dependent only on the number of $\mathrm{I}(1)$ regressors, so breaks should converge faster than they would with an ADL framework that uses lagged levels of oil prices. Finally, the DOLS model incorporates the restriction that the weights of past lags of oil prices sum to one, which an ADL model does not do.

20 The transformation from original pricing formula uses three facts:

$$
\tilde{z}_{t}=\theta_{0} z_{t}+\sum_{r=1}^{p+1} \theta_{r} z_{t-r} \quad z_{t-r}=z_{t}-\sum_{s=0}^{r-1} \Delta z_{t-s} \quad \sum_{r=0}^{p+1} \theta_{r}=1 .
$$

${ }^{21}$ The recovery of the original weights relies on three facts:

$$
\pi_{p}=-\delta \theta_{p+1}-\pi_{q-1}=\delta \theta_{q} \text { for } r=1, \ldots, p \quad \theta_{0}=1-\sum_{r=1}^{p+1} \theta_{r}
$$




\subsection{Detecting structural breaks}

The presence of structural breaks presents an econometric challenge. If LNG prices were determined by a single, simple slope-intercept formula, they could easily be estimated with the Johansen (1988) maximum-likelihood method or the Dynamic OLS model proposed by Saikkonen (1991) and Stock and Watson (1993). These techniques, however, impose constant parameters, which would result in biased and inconsistent estimates in the presence of structural breaks. Furthermore, as documented by Perron (1989) and Gregory and Hansen (1996), if structural breaks are not accounted for in a cointegrating relationship, statistical tests usually suggest that the relationship is spurious when the two series are, in fact, cointegrated.

I estimate the number and positions of breakpoints using tests developed by Bai and Perron 1998, 2003) for a stationary context and extended by Kejriwal and Perron (2008b, 2010) to a cointegrated context. My notation follows theirs. The basis for breakpoint-testing is the sup Wald test for $k$ unknown breaks in the set of coefficients. I denote the sup Wald test statistic as $F_{T}(k)$. Given a minimum allowable segment size $\epsilon$ (which is in terms of percentage of the sample), the procedure finds the vector of break-dates that, when allowed, minimizes the sum of squared residuals (SSR). One then tests the significance of these optimal breaks. Minimization of the SSR is equivalent to maximizing the sup Wald test $\left(F_{T}(k)\right)$. Initial detection of any breaks is done with the double-maximum $U D \max F_{T}(M)$ test of the null hypothesis of no breaks against the alternative of an unknown number of up to $M$ breaks. The test-statistic is simply the maximum sup Wald test for breaks $1, \ldots, M$, that is, $\max _{1 \leq m \leq M} F_{T}(m)$. If I reject the null hypothesis of no breaks, the number of breaks is chosen using sequential break tests $F_{T}(k+1 \mid k)$. These test the null of $k$ breaks against the inclusion of an additional break within one of the $k+1$ segments defined by the $k$ breaks. The point at which the sequential test no longer rejects the null hypothesis of no additional break indicates the true number of breaks. Descriptions of these tests and the robust versions I use can be found in Kejriwal (2008) and Kejriwal and Perron (2010), the latter of which has critical values ${ }^{22}$. I denote the robust versions of the tests using an asterisk: $F_{T}^{*}(k), U D \max F_{T}^{*}(M)$, and $F_{T}^{*}(k+1 \mid k) 23$

\subsection{Estimation}

Pricing formulas for Japan-U.S. LNG cargoes base a given month's LNG prices on a weighted average of oil prices from the previous months. Cross-correlations of LNG and oil prices confirm this: for most series, LNG prices in month $t$ are more correlated with lagged oil prices compared to contemporaneous ones. This is true for levels as well as differences. To choose between the candidate oil benchmarks, Brent crude and JCC, I regress LNG prices against lags zero through

\footnotetext{
${ }^{22}$ Critical values are also available in the paper's online appendix at http://people.bu.edu/perron/papers/cv_ eps152025.pdf However, the authors confirmed that the numbering of the cases is different in the online appendix than the published paper. In particular, category a case 1 in the paper corresponds to case 2 in the appendix.

${ }^{23}$ I did calculate $U D \max F_{T}(M), F_{T}(k)$, and $F_{T}(k+1 \mid k)$, but values were implausibly large, and residuals appear to exhibit substantial persistence, which violates the assumptions of the tests. Kejriwal (2008) uses the robust versions of the tests that I do.
} 
six of each crude oil price separately and choose the benchmark that yields the best fit in terms of the SSR. As expected, the Japanese, South Korean, and Taiwanese LNG prices are all most highly related to the Asian JCC benchmark (with the notable exception of Indonesian imports in South Korea and Taiwan). Spanish imports of LNG from Algeria appear to be pegged to Brent crude, but Qatari and Nigerian imports appear to be linked to JCC. Since Spain competes with Asian buyers for Qatari cargoes, it is not surprising that the oil benchmark would be common with Asian buyers. Brent crude comes from the North Sea, and Algeria sells large quantities of gas to Europe. Thus, a Brent-Algerian LNG link is not surprising. It is unclear why Nigerian LNG - an Atlantic cargo - would be pegged to JCC. For each LNG series, the SSRs from the two regressions and the lag of oil prices most highly correlated with the series are listed with summary statistics in Table 1 .

As suggested by Kejriwal and Perron (2008a), I determine the appropriate number of lagged differences of oil prices (the parameter $p$ ) to include in equation (2) by using the Bayesian information criterion (BIC). I consider rejection of the $U D \max F_{T}^{*}(M)$ statistic at the $5 \%$ level to indicate the presence of at least one break. The number of breaks corresponds to the value $k$ at which the sequential test, $F_{T}^{*}(k+1 \mid k)$, is no longer rejected at the $1 \%$ level ${ }^{24}$ In most cases, the number of breakpoints selected corresponds to the minimum of either the BIC or LWZ information criterion ${ }^{25}$ mentioned by Bai and Perron (1998, 2003) and Kejriwal (2008) ${ }^{26}$ Breakpoint test statistics are available in Tables 3, 4, and 5. In the bottom of each table, the rows BIC, LWZ, $S S R_{k}, F_{T}^{*}$, $F_{T}^{*}(k+1 \mid k)$ and $\min \left(\Delta T_{i}\right)$ correspond to the BIC and LWZ information criterion, the sum of squared residuals when $k$ optimal breaks are allowed, the sup-Wald test for zero breaks versus an alternative of $k$ breaks, the sequential test of $k+1$ breaks versus the null of $k$ breaks, and the minimum length among all $k+1$ regimes corresponding to the $k$ breaks ${ }^{27}$ Equation (2) and associated test statistics are estimated separately for each regime. For breakpoint tests, I estimate the long-run variance of $u_{t}$ as suggested by Kejriwal and Perron (2010). This is an Andrews (1991) HAC estimator that uses residuals from the model estimated under both null and alternative hypothesis. Finally, I calculate the implied parameters for an LNG pricing formula - equation (1) - and compute standard errors using the delta-method and regime-specific long-run variances calculated with an Andrews (1991) estimator. These estimates of average pricing formulas are given in Tables 6, 7, 8, and 9 .

\footnotetext{
${ }^{24}$ Unfortunately, the minimum break-sizes I admit in the Japan-Indonesia and Japan-U.S. regressions are smaller than those for which the authors provide critical values. One contract accounting for more than $50 \%$ of Indonesian volumes expired in 2011, and the U.S. export license changed from long-term to short-term in 2009. Allowing these breaks requires $\epsilon<0.15$. In this case, I use the Liu et al. (1997) (LWZ) criterion, the minimum of which corresponds to a sharp decrease in the $F_{T}^{*}(k+1 \mid k)$ test that would clearly indicate a break were $\epsilon \geq 0.15$.

${ }^{25}$ See Kejriwal (2008) for formulas.

${ }^{26}$ Breakpoint estimation is done using the $\mathbf{R}$ package strucchange, modified slightly to meet my needs. Unfortunately, critical values for the case where $\epsilon=0.10$ are not provided, so I cannot use the $F_{T}^{*}(k+1 \mid k)$ test for Japan-Indonesia and Japan-U.S. prices. For these two cases I use the LWZ criterion, which selected the breakpoints that would have been selected were the $\epsilon=0.15$ critical values to have been used.

${ }^{27}$ The minimum BIC and LWZ for each model are starred, and stars on the breakpoint tests indicate rejection at the 10\%, $5 \%$ and 1\% levels for 1, 2 and 3 stars, respectively. sup Wald tests are not starred if the double-maximum test or sequential tests do not suggest the presence of a corresponding break.
} 
Figure 7: Series with breaks (plus Brent crude)

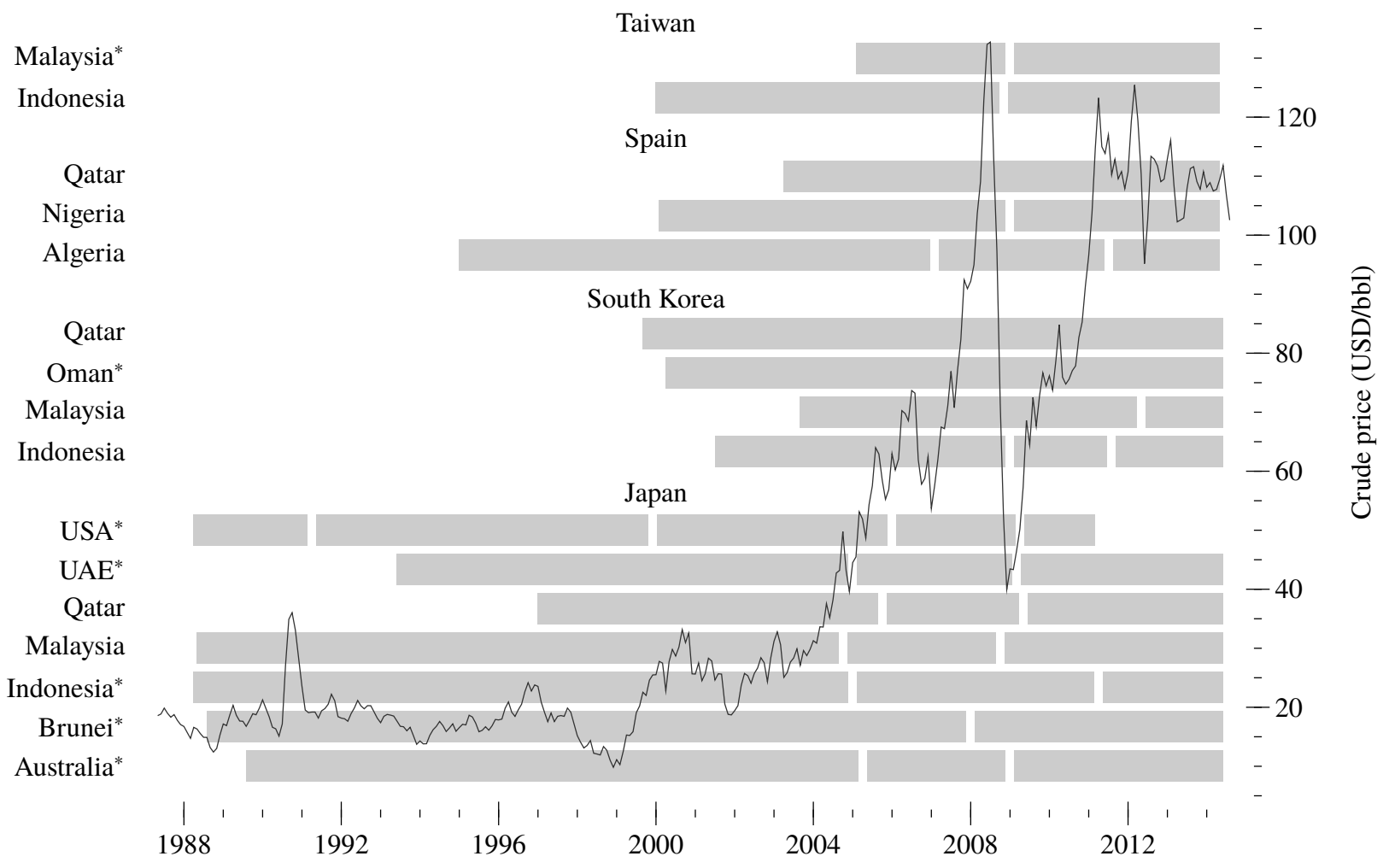

Source: Author's calculations and EIA

\section{$7 \quad$ Results}

Figure 7 represents each price series as a gray bar, and estimated breakpoints appear as white, vertical breaks. The length of the bar corresponds to the length of the series I use, not the full history of trade. Starred series are the ones which appear to have less heterogeneity in contracts and which are most likely to represent actual contract terms and revisions. Brent crude prices are overlaid for reference. Figures $8 \mathrm{a}$ and $8 \mathrm{~b}$ depict scatter-plots of average LNG prices versus oil prices. The vertical axis is LNG prices, and the horizontal axis corresponds to the lag of the crude benchmark most highly correlated with each LNG price series ${ }^{28}$ Each regime is coded by grayscale and symbol shape. The solid diagonal line represents rough thermal parity 29 The same information is plotted in the time-dimension in Figures $9 \mathrm{a}$ and $9 \mathrm{~b}$

Before proceeding to examine individual price series, three general comments are worth making. First, there is considerable variation in the lags used to form oil price benchmarks $\tilde{z}_{t}$. Averaging over several lags of oil prices should serve to dampen the volatility of contracted LNG prices, but it is unclear why some pricing formulas use longer lags than others. In general, estimates

\footnotetext{
${ }^{28}$ Table 1 lists the benchmark and lag plotted.

${ }^{29}$ Thermal parity is approximately 1 MMBtu of gas to $0.172 \mathrm{bbl}$ crude since $1 \mathrm{bbl}$ of oil contains about $5.8 \mathrm{MMBtu}$ of energy.
} 
Figure 8: Scatter plots of LNG versus lag of oil with maximal correlation

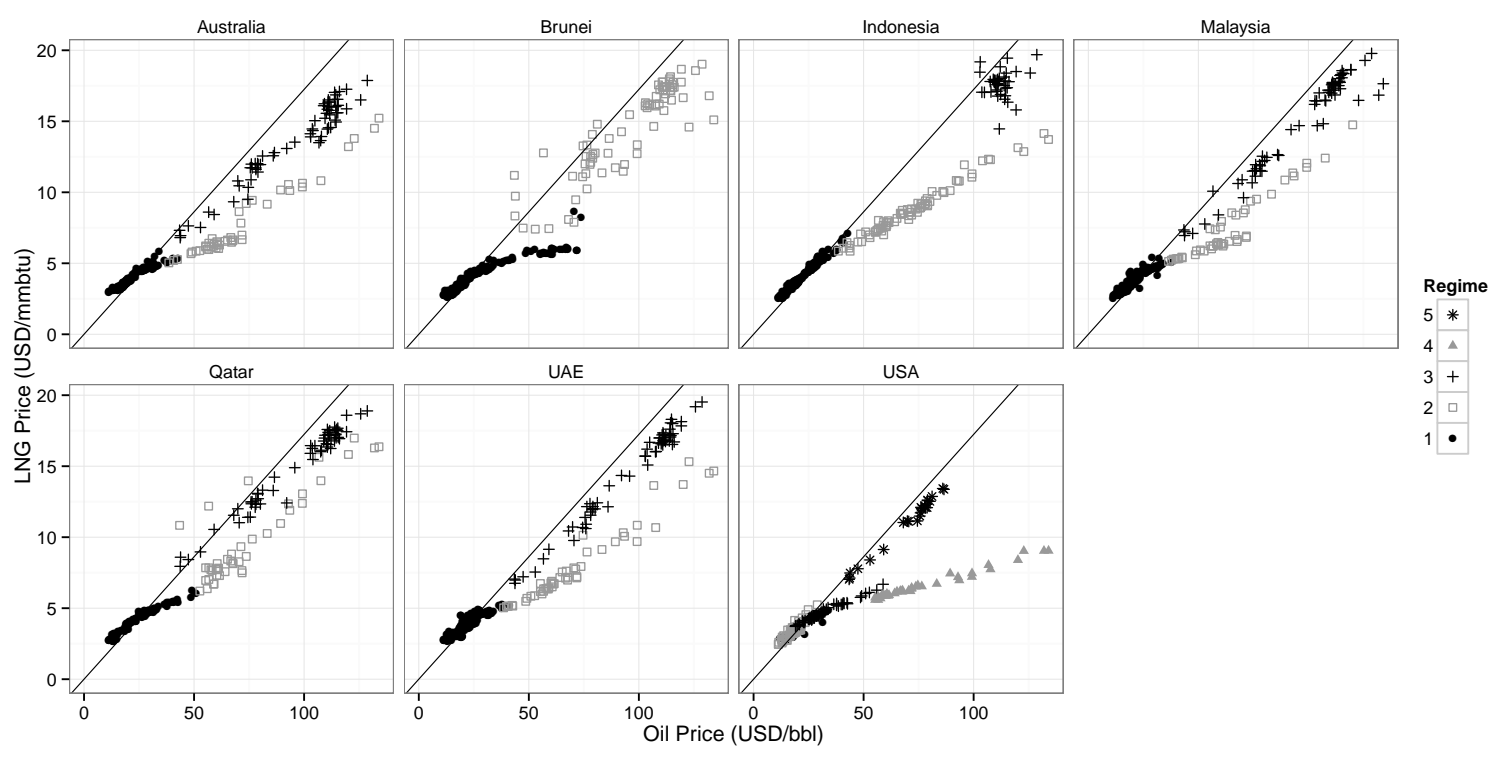

(a) Japan

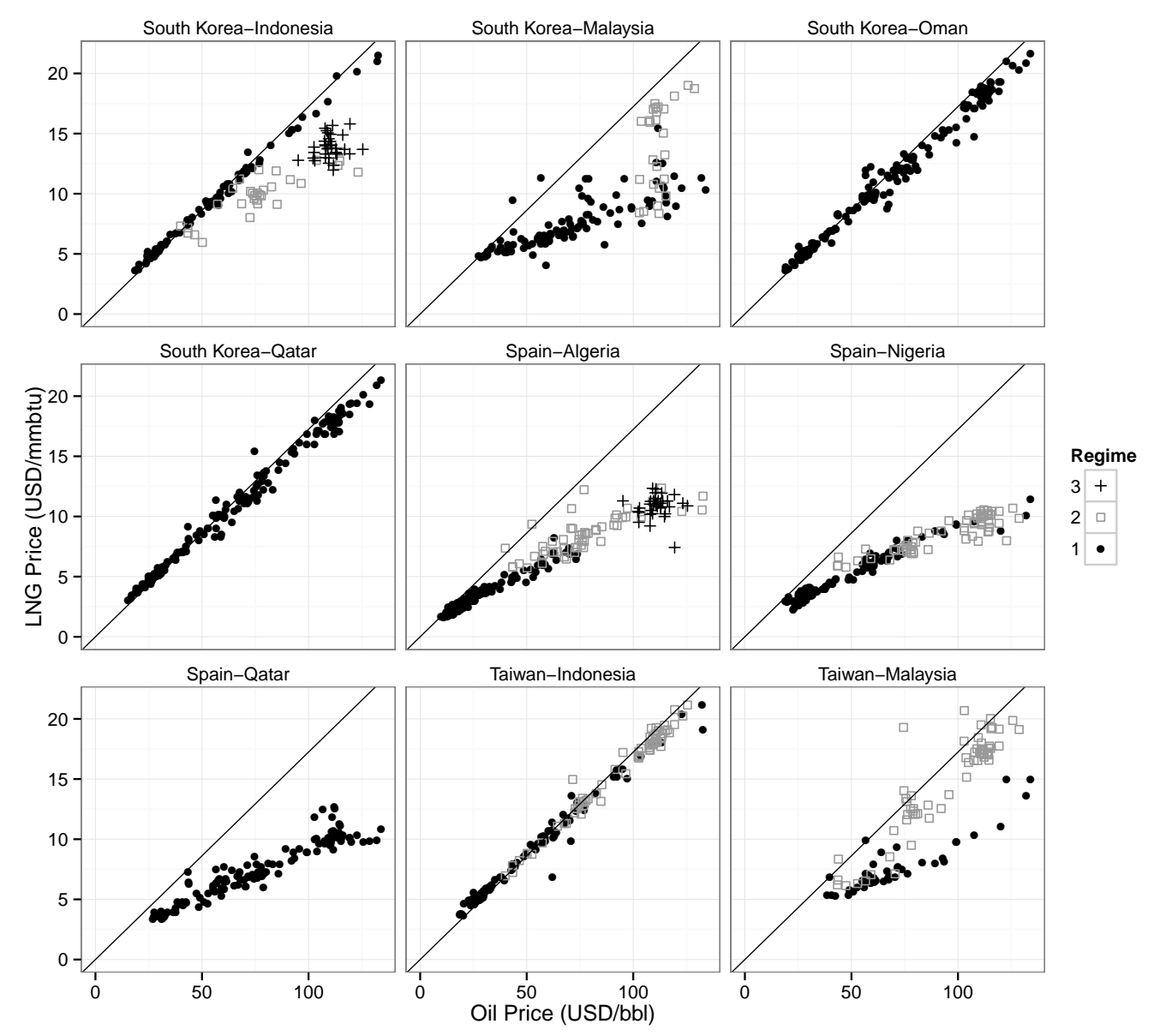

(b) S. Korea, Taiwan, and Spain 
Figure 9: Time-series of LNG and most correlated lag of oil prices

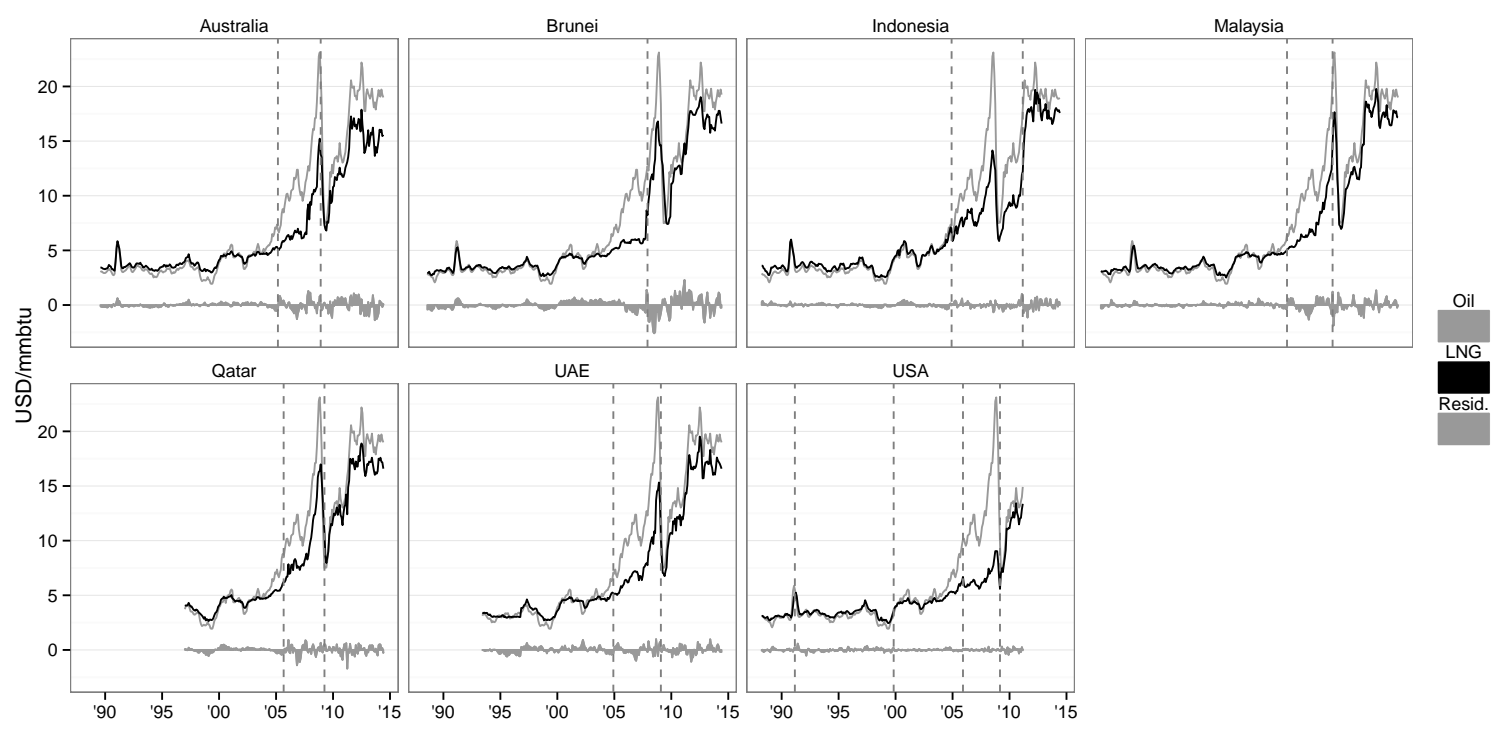

(a) Japan

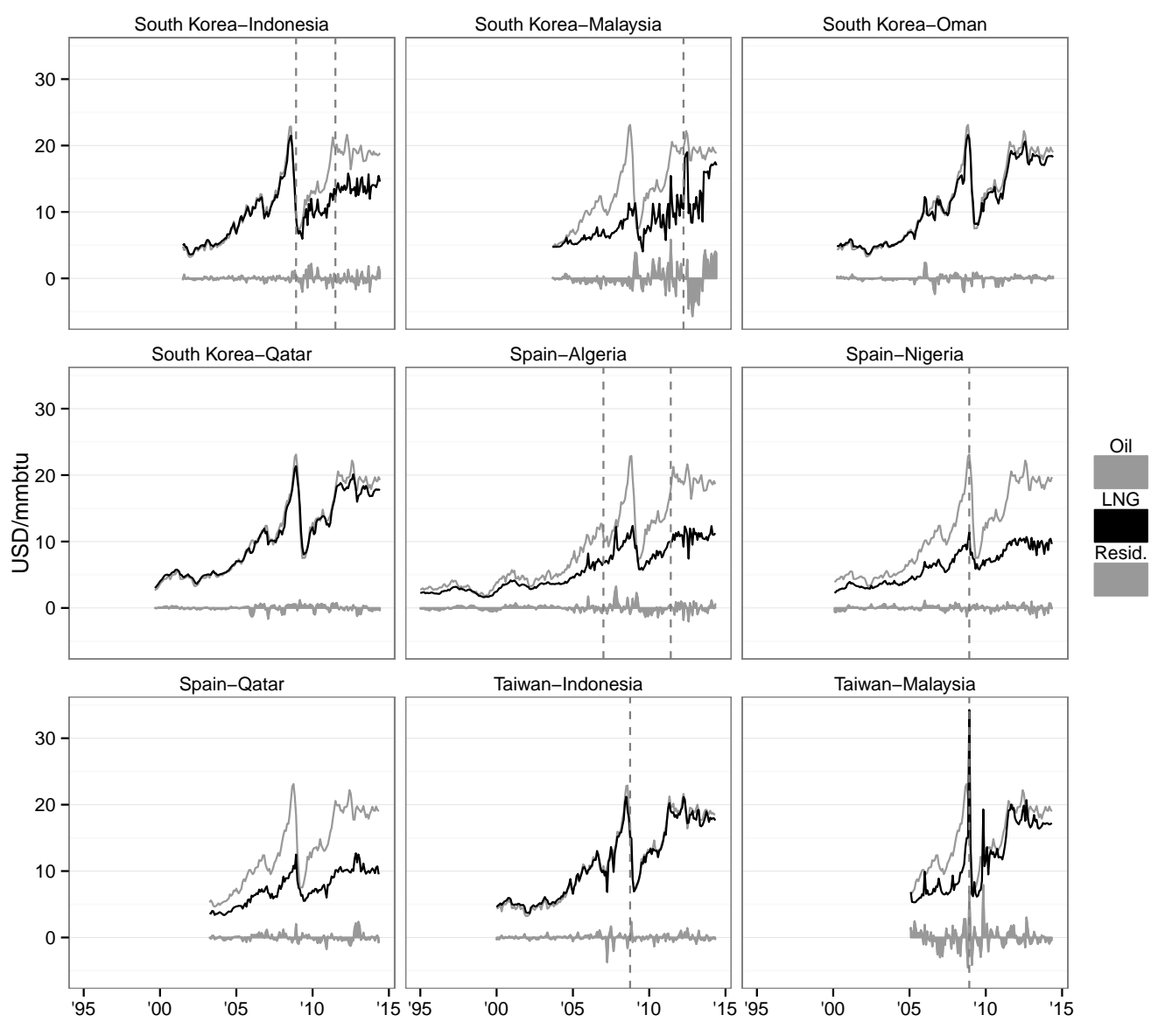

(b) S. Korea, Taiwan, and Spain 
of average pricing formulas have one or two particularly significant weights for lagged oil prices $\left(\theta_{r}\right)$. These will correspond to the most important lags in pricing benchmarks, and significant pricing lags range from the contemporaneous $\left(\theta_{0}\right)$ to the sixth $\left(\theta_{6}\right)$. Most parameter estimates for these significant lags lie in the interval $[0,1]$ as expected, though some regressions with poorer fits have parameters well outside of this range. Second, the link with oil prices is very strong, and when the estimated breaks are allowed, Dickey-Fuller tests for the stationarity of the residuals from equation (2) all exceed 1\% critical values for the Engle-Granger cointegration test. This means that despite increases in the share of spot volumes and in contract heterogeneity, average LNG prices are cointegrated with crude oil prices. Third, it bears reiterating that breakpoints are estimated under the assumption of constant variance and the null hypothesis of no breaks. Also, the tests rely on infill asymptotics where the distance between observations shrinks to zero, but my data are monthly. Thus, breakpoint estimates should be interpreted with some caution. For instance, casual inspection of the Japan-Brunei relationship in Figure 8a suggests that the slope in the initial regime (filled black circles) changes as oil prices rise and that the variance is higher in the second period (hollow gray squares) ${ }^{30}$ Because of the changes in variance over time, I choose not to calculate confidence intervals for breakpoints even though Kejriwal and Perron (2008b) explain how to do so when the variance is constant.

\subsection{Japan}

Empirical Japanese pricing relationships appear to have undergone more changes than those of other importers. Figure 7 shows two clusters of breaks in Japanese contracts: during the periods 2004-2005 and 2008-2009. Initial pricing regimes as plotted in Figure 8a seem to hew relatively close to thermal parity since the black circles fall along the diagonal line. When oil prices head above $\$ 25 / \mathrm{bbl}$, however, LNG prices do not rise as fast; consequently, they fall below thermal parity. This behavior, which is suggestive of S-curve kinks in the LNG-oil pricing relationship, corresponds to time-breaks in some series in 2004 and 2005. Good examples of this are LNG from the U.A.E., which was imported under only one contract; from Indonesia, which was imported under five stable contracts and has a very tight fit; and from Malaysia.

\footnotetext{
${ }^{30}$ Breakpoint tests do not show that Brunei has a statistically significant break that corresponds to an S-curve (which would occur within the initial black circles regime) when the entire series is used to form test statistics. However, the variance in the first segment is much smaller than the variance in the second, so breakpoint tests might have missed a kink corresponding to an S-curve. (Such a possibility vanishes, of course, as the interval between observations goes to zero.) If only the first segment from 1988(8) to 2007(12) is tested for a break of a minimum size $\epsilon=0.15$, the $U D \max F_{T}^{*}(M)$ and $F_{T}^{*}(k+1 \mid k)$ tests reject the null of no breaks in favor of a single break at $2003(12)$ at the $1 \%$ level. The break corresponds to what could be the start of the shallow upper tail of an S-curve beginning in the $\$ 30.55-\$ 31.07 / \mathrm{bbl}$ range, and the endpoints correspond to average JCC prices in 2003(12) and 2004(1), respectively. Rather than a single slope parameter of 0.064 , the two slope parameters would be 0.119 and 0.048. While the resulting plots are visually quite convincing, this is an ad-hoc test, so I do not report the results in tables. Nevertheless, it is illustrative. Such a procedure violates the asymptotic framework upon which the tests are based, specifically the notion that the interval between observations shrinks and the duration of the series is fixed. Graphs suggest that Malaysian and Qatari prices might also exhibit undetected S-curve behavior.
} 
2008-2009 volatility In later regimes, LNG prices move higher and appear to regain rough thermal parity with oil prices. This approximately corresponds to the 2008-2009 cluster of breaks (evident especially in Figure 7). This round of breaks may be the one that Li et al. (2014) state brought Japanese prices into an Asian "convergence club." Though the 2008-2009 period corresponds to major oil price volatility and a global financial crisis, a number of empirical breaks likely correspond to changes in pricing terms. The U.A.E. break in 2009 comes from LNG imported under a single contract plus very few spot volumes, as does the December 2007 Brunei break. The U.S. break corresponds to a switch from long-term to short-term contracts, and the Australian break coincides with the replacement of a single LTC representing almost half of all Japanese imports from Australia with several smaller, separate LTCs. It is not clear a priori how global financial turmoil would have affected the LNG-oil relationship, and from an estimation standpoint, additional variance in oil prices will help, not hinder, identification of econometric models. Nevertheless, the financial crisis could have affected empirical pricing relationships in unexpected ways. I choose not to explore this possibility.

Fukushima It is interesting to note that many series do not have breaks after the Fukushima incident since, as Medlock (2014) observes, spot prices for Asian LNG jumped dramatically immediately following the tsunami. A notable exception is the Japan-Indonesia trade, which displays a clear break precisely in March 2011. This date, however, also coincides with the expiry of a large share of the Japan-Indonesia contracts and a sharp fall in volumes, not just the Fukushima disaster 31 The stability of the LNG-oil pricing relationship after the Fukushima incident suggests that LTCs function as a form of insurance against unexpected shocks since they tie prices in a thin market to a deep, liquid one. A quantity shock to one country in the very deep crude oil market may not represent a relatively large change in global crude oil volumes; however, a shock to one country in the LNG market is likely to represent a much larger disruption proportionally and induce more volatility in prices.

S-curves One explanation for the larger number of Japanese breaks is that only Japanese pricing formulas appear to exhibit S-curve behavior. Since oil prices rose steadily in the mid-2000s, an S-curve could be identified as a break in time, not only a kink over the range of oil prices. Two series exhibit very clear S-curve behavior that corresponds to breaks in time: the United States and Indonesia in 1999(11) and 2004(12), respectively ${ }^{32}$ In each case, the estimated slope parameter, $\hat{\delta}$, falls by almost 50\%. When the U.S. break occurs between November and December 1999, average JCC prices were $\$ 23.25$ and $\$ 24.94$, respectively. The Kenai export license specifies a kink precisely in the $\$ 25-\$ 26 / \mathrm{bbl}$ range ${ }^{33}$ The Indonesia break at 2004(12)-2005(1) corresponds to average JCC prices of $\$ 39.82$ and then $\$ 38.54 / \mathrm{bbl}$, which would mean that the Indonesia kink is higher than the

\footnotetext{
${ }^{31}$ Figure 5 shows a large drop in both actual total volumes and contracted volumes from Indonesia.

${ }^{32}$ Brunei may as well, as described in Footnote 30

${ }^{33}$ Similarly, Flower (2011) states that SPAs between Qatar and Japan use an S-curve with an upper kink at $\$ 24 /$ bbl. For these contracts the slope parameter is 0.1485 in the mid-range, and in the tails it is 0.07 .
} 
U.S. one.

\subsection{South Korea, Taiwan, and Spain}

South Korea, Taiwan, and Spain are all major importers of LNG, though they purchase less than Japan. Even though these LNG prices appear to be cointegrated with oil prices when breaks are not allowed, if breaks are present, they will bias parameter estimates; thus, I still choose to investigate these series for breaks. Six of these countries' nine series exhibit breaks; however, there are fewer breaks per relationship: just two have more than single break. Since there are fewer breaks, the pricing relationships and underlying pricing formulas appear to be more stable. Furthermore, slope estimates $-\hat{\delta}$ in Tables 8 and 9 and scatter-plots in Figure $8 \mathrm{~b}$ suggest that revisions have tended to consist of relatively minor modifications to slopes and lags used in constructing average oil prices. Given that Taiwan and Korea each have a single LNG buyer (CPC and Korea Gas Corporation, respectively) and that a number of exporting countries have a single company selling LNG, not multiple exporting firms, it seems reasonable to expect less heterogeneity in the pricing of cargoes underlying average import prices, even if there are multiple LTCs in force.

South Korea and Taiwan Slopes for South Korean and Taiwanese pricing relationships are relatively steep (with the exception of imports from Malaysia and later South Korea-Indonesia imports). Slope parameters for these relationships appear to be similar, and estimates stay in a relatively narrow range between 0.152 and 0.158 , which is substantially higher than Japanese values and closer to both thermal parity $(0.172)$ and the 0.1485 rule-of-thumb.

The fits for the Korea-Oman (a single LTC), Korea-Qatar, and Taiwan-Indonesia series are close. The first two exhibit no breaks (even though shares of spot imports exhibit substantial variation). Breakpoint tests suggest that the Taiwan-Indonesia relationship has a break in October 2008, but actual estimates change little. Additionally, there were no Indonesia-Taiwan spot imports around 2008, and the trade corresponds to just two LTCs, which did not start or expire during that time. The second South Korea-Indonesia break in 2011(7) may be the result of large increases in spot volumes, which are clearly evident in Figure 6. The implausible slope and intercept estimates during the third regime should be, therefore, less surprising. The December 2008 break, however, cannot be explained by changes in the number of LTCs or spot volumes (which are zero).

Fits for Korean and Taiwanese imports from Malaysia are the worst for any series in terms of long-run variance estimates, and some of the oil price weights $\left(\theta_{r}\right)$ lie well outside the $[0,1]$ interval. The slope parameters are shallower (particularly in the initial South Korea-Malaysia regime, which has a slope of 0.065), but it is not clear why this is so. It is worth noting that the Taiwan-Malaysia trade takes place under only one LTC, and spot imports are minimal or zero, with the exception of the 2005-2008 period. There is more variation in Korean LTCs and spot volume shares. The poorer fits suggest that the econometric model may not fully capture the actual pricing mechanism in these contracts. 
Spain Spain is the only European importer I consider, and changes in total volumes, spot-shares, and number of contracts are among the largest. This suggests that my Spanish prices will be aggregating over the most heterogeneous cargoes, so estimates should be interpreted as average pricing terms, not actual pricing terms. Empirical Spanish pricing relationships appear to have much shallower slope parameters in the 0.68-0.90 range, which is roughly what the tails of Japanese S-curves specify. Because of this, LNG prices have increased much less in Spain than for Asian buyers, even though Spain competes with Asia for Qatari cargoes. Shallower slopes are possibly due to the fact that Spain also has access to European gas markets and, therefore, more elastic demand for LNG. Furthermore, transportation costs may be prohibitively high for African LNG to reach Asia (historically, the Africa-Asia trade has not been large), so African nations may not be able to arbitrage differences between Asian and European LNG prices. The large differences in pricing between the Atlantic and Pacific markets for LNG suggest that the two are still weakly arbitraged. Further work is needed to determine whether Spanish LNG prices are more tightly linked to continental European gas prices or oil markets.

\section{Conclusion}

This paper systematically examines the empirical relationship between LNG and crude oil prices using customs data from Japan, South Korea, Taiwan, and Spain. Historically, these are the four most significant players in the LNG market, and the price series and contract data I examine correspond to a large share of these countries' imports. Oil-indexation of long-term LNG contract prices should mean that statistical evidence for cointegration between oil and LNG prices is very strong; however, this is not the case for Japan. Motivated by this puzzle, I allow for structural breaks in the LNG-oil price relationship for each series, which resolves the puzzle.

Recent work on global gas markets by Neumann et al. (2006), Neumann and Cullmann (2012), and Li et al. (2014) has shied away from a cointegration framework where prices are tightly linked in favor of the Kalman filter that captures gradual price convergence. These papers also acknowledge the important role of oil-indexed long-term contracts. I return to a cointegration framework to explicitly capture oil-indexation terms. By allowing for discrete structural breaks, I show that the expected, empirical LNG-oil link is very strong in Japan, which was not otherwise verifiable in a simple cointegration framework. By linking the statistical analysis with an examination of data on long-term contracts, I am able to identify possible causes for breaks and to identify series that can be interpreted as truly representative of long-term contracts.

Empirical Japanese LNG-oil pricing relationships change more often than those of other countries. Major changes or heterogeneity in LNG portfolios leads to some breaks, but other breaks seem due to contract revisions. Some of the revisions are likely to correspond to the use of S-curves in pricing formulas, while others may be due to the elimination of S-curves in contracts when markets were tighter and LNG was trading at a relatively steep discount to crude oil on an energy-parity basis. The fact that the LNG-oil relationship did not change much in response to the Fukushima 
incident is consistent with the idea that long-term LNG contracts function as a form of insurance against unexpected shocks, stabilizing cash flows and allowing firms to finance investment projects with more debt.

Korean and Taiwanese contracts, which are all linked to a single national importer in each country, give rise to much simpler and more stable empirical relationships. The contracts appear to have undergone little revision, if any. Additionally, slope-intercept formulas were historically steeper, meaning these two countries felt a greater impact from higher oil prices compared to Japan. In recent years, however, the slopes of Japanese contracts have more closely resembled those in South Korea and Taiwan. Spanish contracts are substantially different from the Asian contracts, with few revisions and much shallower slopes.

The focus of this paper has been on how and when empirical pricing relationships in LNG markets have changed as a way to understand how underlying pricing formulas in long-term contracts have developed. It appears that LNG prices continue to be indexed to oil prices, though the relationship between prices can be substantially more complex than industry rules of thumb predict. It will be interesting to re-evaluate empirical oil-LNG relationships in the coming years to see how they change given the emergence of large new LNG supplies, the dramatic drop in oil prices beginning in 2014, the possible use of the U.S. Henry Hub in LNG indexation terms, and increasing spot transactions. 


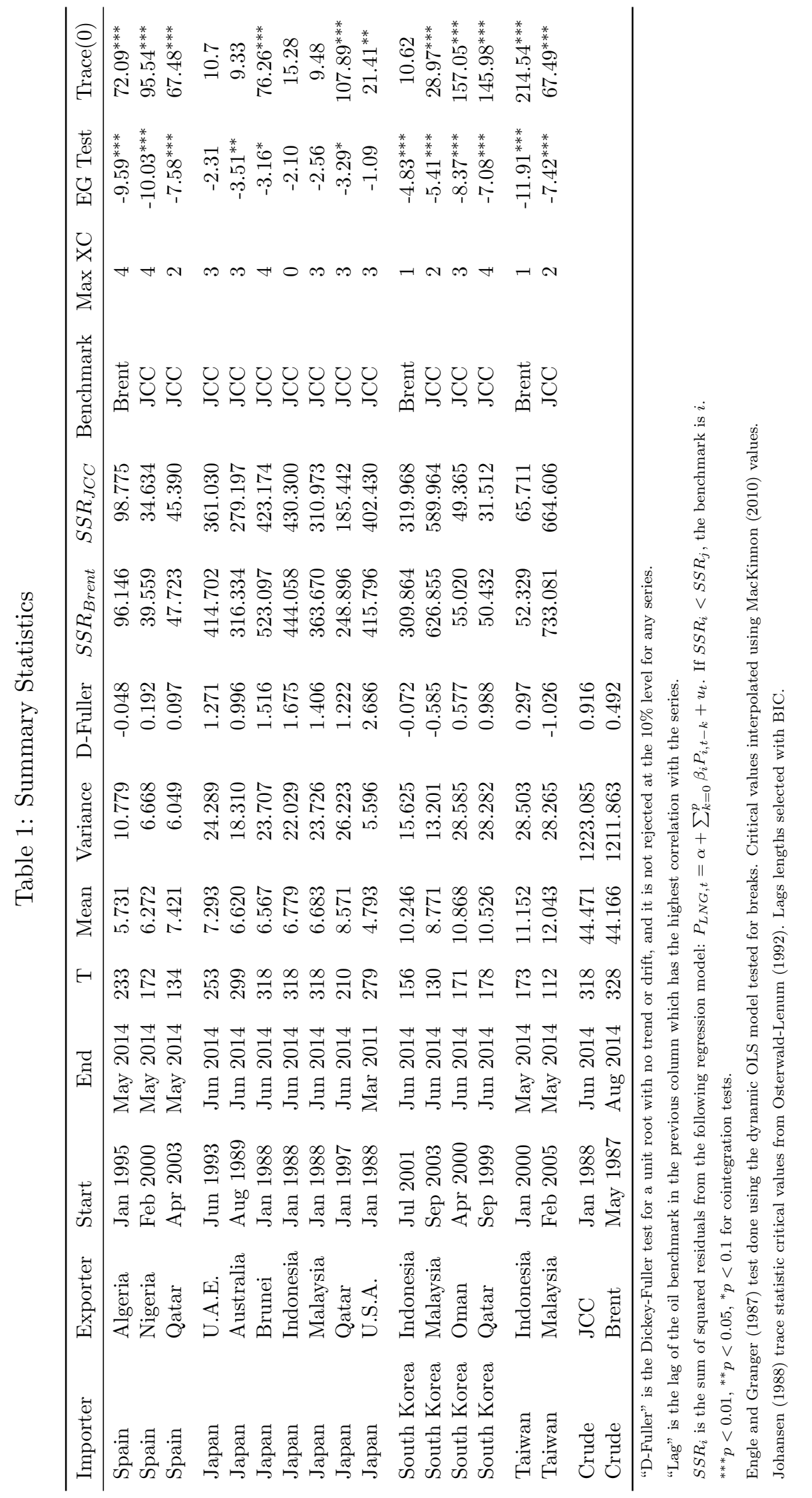


Table 2: Counts of long-term contracts in force in given year

\begin{tabular}{|c|c|c|c|c|c|c|c|c|c|c|c|c|c|c|}
\hline & 2000 & 2001 & 2002 & 2003 & 2004 & 2005 & 2006 & 2007 & 2008 & 2009 & 2010 & 2011 & 2012 & 2013 \\
\hline \multicolumn{15}{|l|}{ Japan } \\
\hline U.A.E. & 1 & 1 & 1 & 1 & 1 & 1 & 1 & 1 & 1 & 1 & 1 & 1 & 1 & 1 \\
\hline Australia & 1 & 1 & 1 & 1 & 3 & 5 & 7 & 7 & 7 & 17 & 16 & 18 & 18 & 18 \\
\hline Brunei & 1 & 1 & 1 & 1 & 1 & 1 & 1 & 1 & 1 & 1 & 1 & 1 & 1 & 1 \\
\hline Indonesia & 5 & 5 & 5 & 5 & 5 & 5 & 5 & 5 & 5 & 5 & 5 & 5 & 4 & 4 \\
\hline Malaysia & 6 & 6 & 7 & 7 & 8 & 10 & 10 & 11 & 11 & 11 & 12 & 13 & 13 & 13 \\
\hline Qatar & 2 & 2 & 2 & 2 & 2 & 2 & 2 & 2 & 2 & 2 & 2 & 3 & 4 & 4 \\
\hline U.S.A. & 1 & 1 & 1 & 1 & 1 & 1 & 1 & 1 & 1 & 1 & & & & \\
\hline \multicolumn{15}{|l|}{ Korea } \\
\hline Indonesia & 3 & 3 & 3 & 3 & 3 & 4 & 4 & 4 & 4 & 4 & 4 & 4 & 4 & 4 \\
\hline Malaysia & 1 & 1 & 1 & 2 & 2 & 2 & 2 & 2 & 3 & 3 & 3 & 2 & 2 & 2 \\
\hline Oman & 1 & 1 & 1 & 1 & 1 & 1 & 1 & 1 & 1 & 1 & 1 & 1 & 1 & 1 \\
\hline Qatar & 1 & 1 & 1 & 1 & 1 & 1 & 1 & 2 & 2 & 2 & 2 & 2 & 3 & 3 \\
\hline \multicolumn{15}{|l|}{ Spain } \\
\hline Algeria & 1 & 1 & 1 & 4 & 4 & 3 & 3 & 3 & 3 & 3 & 3 & 3 & 3 & 3 \\
\hline Algeria-Nigeria-Italy & & & 1 & 1 & 1 & 2 & 2 & 3 & 3 & 3 & 3 & 3 & 3 & 3 \\
\hline Nigeria & & & & 1 & 1 & 1 & 4 & 4 & 4 & 5 & 5 & 5 & 5 & 5 \\
\hline Nigeria (w/ U.S.A.) & 1 & 1 & 2 & 2 & 2 & 2 & 2 & 2 & 2 & 2 & 2 & 2 & 2 & 2 \\
\hline Nigeria (w/ Mex./U.S.A.) & & & & & & & 1 & 1 & 1 & 1 & 1 & 1 & 1 & 1 \\
\hline Qatar & & 1 & 2 & 3 & 4 & 6 & 6 & 6 & 6 & 6 & 5 & 4 & 4 & 2 \\
\hline \multicolumn{15}{|l|}{ Taiwan } \\
\hline Indonesia & 2 & 2 & 2 & 2 & 2 & 2 & 2 & 2 & 2 & 2 & 2 & 1 & 1 & 1 \\
\hline Malaysia & 1 & 1 & 1 & 1 & 1 & 1 & 1 & 1 & 1 & 1 & 1 & 1 & 1 & 1 \\
\hline
\end{tabular}

Calculations by author based on data from GIIGNL.

Thanks to Weiran Yan, Wei Yang Tham, Ji Soo Kim and Kate Kremling for assistance in compiling contracts data. 
Table 3: Break tests (Japan)

\begin{tabular}{|c|c|c|c|c|c|}
\hline \multicolumn{6}{|c|}{ Japan-Australia: $T=299$} \\
\hline & & & & & Break $_{k+1}$ \\
\hline$k=1$ & & & & $2008(12)$ & $2005(3)$ \\
\hline$k=2$ & & & $2005(3)$ & 2008(12) & $2000(3)$ \\
\hline$k=3$ & & $2000(3)$ & $2005(3)$ & $2008(12)$ & 1995(9) \\
\hline \multirow[t]{2}{*}{$k=4$} & 1995(9) & $2000(5)$ & $2005(3)$ & $2008(12)$ & - \\
\hline & $k=0$ & $k=1$ & $k=2$ & $k=3$ & $k=4$ \\
\hline $\mathrm{BIC}$ & 0.06 & -1.37 & $-1.51^{*}$ & -1.45 & -1.34 \\
\hline LWZ & 0.20 & $-1.07^{*}$ & -1.05 & -0.82 & -0.56 \\
\hline$S S R_{k}$ & & 59.38 & 44.92 & 41.97 & 40.83 \\
\hline UDMax & $21.23^{* * *}$ & & & & \\
\hline$F_{T}^{*}$ & & $21.23^{* * *}$ & $14.47^{* * *}$ & 9.94 & 7.53 \\
\hline$F_{T}^{*}(k+1 \mid k)$ & & $14.72^{* *}$ & 5.76 & 2.38 & -0.00 \\
\hline $\min \left(\Delta T_{i}\right)$ & & 66 & 45 & 45 & 45 \\
\hline
\end{tabular}

\begin{tabular}{|c|c|c|c|c|c|}
\hline $\mathbf{J}$ & $-\mathrm{Dr}$ & 1: $1=$ & $1 \quad \epsilon T$ & $7 \quad \epsilon=0.1$ & Break $_{k+1}$ \\
\hline$k=1$ & & & & $2007(12)$ & $2003(12)$ \\
\hline$k=2$ & & & $2004(9)$ & $2008(8)$ & $2000(3)$ \\
\hline$k=3$ & & $2000(3)$ & $2004(9)$ & $2008(8)$ & 1993(1) \\
\hline \multirow[t]{2}{*}{$k=4$} & 1993(1) & $2000(4)$ & $2004(9)$ & $2008(8)$ & - \\
\hline & $k=0$ & $k=1$ & $k=2$ & $k=3$ & $k=4$ \\
\hline BIC & 0.44 & -0.75 & $-0.94^{*}$ & -0.78 & -0.60 \\
\hline LWZ & 0.64 & $-0.32^{*}$ & -0.28 & 0.11 & 0.51 \\
\hline$S S R_{k}$ & & 103.18 & 71.07 & 69.43 & 69.04 \\
\hline UDMax & $15.04^{* *}$ & & & & \\
\hline$F_{T}^{*}$ & & $15.04^{* *}$ & 9.72 & 6.31 & 4.60 \\
\hline$F_{T}^{*}(k+1 \mid k)$ & & 7.68 & 2.72 & 0.64 & -0.00 \\
\hline $\min \left(\Delta T_{i}\right)$ & & 78 & 47 & 47 & 47 \\
\hline
\end{tabular}

\begin{tabular}{|c|c|c|c|c|c|}
\hline \multicolumn{6}{|c|}{ Japan-Indonesia: $T=315$} \\
\hline & & & & & Break $_{k+1}$ \\
\hline$k=1$ & & & & $2011(3)$ & $2004(12)$ \\
\hline$k=2$ & & & 2004(12) & 2011(3) & $2001(8)$ \\
\hline$k=3$ & & $2001(8)$ & $2004(12)$ & $2011(3)$ & 1997(5) \\
\hline \multirow[t]{2}{*}{$k=4$} & 1997(5) & $2001(8)$ & 2004(12) & $2011(3)$ & $2007(12)$ \\
\hline & $k=0$ & $k=1$ & $k=2$ & $k=3$ & $k=4$ \\
\hline BIC & 0.42 & -1.97 & $-2.57^{*}$ & -2.55 & -2.49 \\
\hline LWZ & 0.53 & -1.73 & $-2.19^{*}$ & -2.03 & -1.84 \\
\hline$S S R_{k}$ & & 35.79 & 17.61 & 16.22 & 15.38 \\
\hline UDMax & 22.63 & & & & \\
\hline$F_{T}^{*}$ & & 22.30 & 22.63 & 16.65 & 13.24 \\
\hline$F_{T}^{*}(k+1 \mid k)$ & & 37.26 & 10.64 & 8.23 & 8.31 \\
\hline $\min \left(\Delta T_{i}\right)$ & & 39 & 39 & 39 & 39 \\
\hline
\end{tabular}

\begin{tabular}{|c|c|c|c|c|c|}
\hline & & & & & Break $_{k+1}$ \\
\hline$k=1$ & & & & $2008(9)$ & $2004(9)$ \\
\hline$k=2$ & & & $2004(9)$ & 2008(9) & $2000(2)$ \\
\hline$k=3$ & & $2000(2)$ & $2005(2)$ & $2009(2)$ & 1996(2) \\
\hline \multirow[t]{2}{*}{$k=4$} & $1996(6)$ & $2000(6)$ & $2005(2)$ & $2009(2)$ & 1992(4) \\
\hline & $k=0$ & $k=1$ & $k=2$ & $k=3$ & $k=4$ \\
\hline BIC & 0.12 & -1.39 & $-1.71^{*}$ & -1.66 & -1.54 \\
\hline LWZ & 0.26 & -1.09 & $-1.26^{*}$ & -1.05 & -0.77 \\
\hline$S S R_{k}$ & & 61.91 & 39.32 & 36.50 & 36.20 \\
\hline UDMax & $21.52^{* * *}$ & & & & \\
\hline$F_{T}^{*}$ & & $21.52^{\text {*** }}$ & $17.38^{* * *}$ & 6.07 & 4.49 \\
\hline$F_{T}^{*}(k+1 \mid k)$ & & $27.04^{* * *}$ & 6.19 & 0.52 & 0.14 \\
\hline $\min \left(\Delta T_{i}\right)$ & & 69 & 48 & 48 & 48 \\
\hline
\end{tabular}

\begin{tabular}{|c|c|c|c|c|c|}
\hline \multicolumn{3}{|c|}{ Japan-Qatar: $T=210$} & $T-32$ & $\epsilon=0.152$ & \multirow[b]{2}{*}{ Break $_{k+1}$} \\
\hline & & & & & \\
\hline$k=1$ & & & $2008(8)$ & & $2011(4)$ \\
\hline$k=2$ & & $2005(9)$ & $2009(4)$ & & $2000(8)$ \\
\hline$k=3$ & & $2005(1)$ & $2008(8)$ & 2011(4) & $2000(8)$ \\
\hline \multirow[t]{2}{*}{$k=4$} & $2000(8)$ & $2005(12)$ & $2008(8)$ & 2011(4) & 2003(4) \\
\hline & $k=0$ & $k=1$ & $k=2$ & $k=3$ & $k=4$ \\
\hline BIC & 0.08 & -1.29 & -1.42 & $-1.42^{*}$ & -1.34 \\
\hline LWZ & 0.30 & $-0.82^{*}$ & -0.70 & -0.45 & -0.11 \\
\hline$S S R_{k}$ & & 37.60 & 26.25 & 20.73 & 17.88 \\
\hline UDMax & $19.94^{* * *}$ & & & & \\
\hline$F_{T}^{*}$ & & $19.94^{* * *}$ & $14.08^{* * *}$ & 10.74 & 9.36 \\
\hline$F_{T}^{*}(k+1 \mid k)$ & & $20.79^{* * *}$ & 14.06 & 13.13 & 1.87 \\
\hline $\min \left(\Delta T_{i}\right)$ & & 70 & 43 & 32 & 32 \\
\hline
\end{tabular}

\begin{tabular}{|c|c|c|c|c|c|}
\hline \multicolumn{6}{|c|}{ Japan-U.A.E.: $T=253$} \\
\hline & & & & & Break $_{k+1}$ \\
\hline$k=1$ & & & & $2009(2)$ & $2004(12)$ \\
\hline$k=2$ & & & 2004(12) & $2009(2)$ & 1996(10) \\
\hline$k=3$ & & $2000(4)$ & $2005(10)$ & $2009(2)$ & 1996(10) \\
\hline \multirow[t]{2}{*}{$k=4$} & 1996(10) & $2000(5)$ & $2005(10)$ & $2009(2)$ & - \\
\hline & $k=0$ & $k=1$ & $k=2$ & $k=3$ & $k=4$ \\
\hline $\mathrm{BIC}$ & 0.51 & -1.60 & -1.79 & -1.84 & $-1.87^{*}$ \\
\hline LWZ & 0.66 & -1.27 & $-1.29^{*}$ & -1.16 & -1.01 \\
\hline$S S R_{k}$ & & 38.50 & 27.19 & 22.19 & 18.60 \\
\hline UDMax & $18.53^{* * *}$ & & & & \\
\hline$F_{T}^{*}$ & & $18.53^{* * *}$ & $13.21^{\text {*** }}$ & 10.19 & 9.19 \\
\hline$F_{T}^{*}(k+1 \mid k)$ & & $14.40^{* *}$ & 12.85 & 14.97 & 0.00 \\
\hline $\min \left(\Delta T_{i}\right)$ & & 64 & 50 & 40 & 40 \\
\hline
\end{tabular}

\begin{tabular}{|c|c|c|c|c|c|}
\hline & \multicolumn{2}{|c|}{ Japan-U.S.A.: $T=276$} & \multirow[t]{2}{*}{$\epsilon T=24$} & \multirow[t]{2}{*}{$\epsilon=0.087$} & \multirow{2}{*}{ Break $_{k+1}$} \\
\hline & & & & & \\
\hline$k=1$ & & & & $2009(3)$ & $2004(8)$ \\
\hline$k=2$ & & & $2004(8)$ & $2009(3)$ & 1999(10) \\
\hline$k=3$ & & 1999(10) & $2005(12)$ & $2009(3)$ & 1991(3) \\
\hline \multirow[t]{2}{*}{$k=4$} & 1991(3) & $1999(11)$ & $2005(12)$ & $2009(3)$ & $1995(9)$ \\
\hline & $k=0$ & $k=1$ & $k=2$ & $k=3$ & $k=4$ \\
\hline BIC & 0.49 & -1.80 & -3.01 & -3.25 & $-3.43^{*}$ \\
\hline LWZ & 0.61 & -1.53 & -2.60 & -2.70 & $-2.73^{*}$ \\
\hline$S S R_{k}$ & & 36.64 & 9.64 & 6.67 & 4.97 \\
\hline UDMax & 16.40 & & & & \\
\hline$F_{T}^{*}$ & & 16.40 & 15.39 & 13.26 & 12.55 \\
\hline$F_{T}^{*}(k+1 \mid k)$ & & 27.98 & 18.10 & 30.81 & 12.75 \\
\hline $\min \left(\Delta T_{i}\right)$ & & 24 & 24 & 24 & 24 \\
\hline
\end{tabular}


Table 4: Break tests (South Korea)

South Korea-Indonesia: $T=156 \quad \epsilon T=24 \quad \epsilon=0.154$

\begin{tabular}{|c|c|c|c|c|c|}
\hline & & & & & Break $_{k+1}$ \\
\hline$k=1$ & & & $2009(1)$ & & $2011(7)$ \\
\hline$k=2$ & & & 2008(12) & 2011(7) & $2005(4)$ \\
\hline$k=3$ & & $2007(6)$ & $2009(6)$ & $2011(7)$ & $2005(6)$ \\
\hline \multirow[t]{2}{*}{$k=4$} & $2005(6)$ & $2007(6)$ & $2009(6)$ & $2011(7)$ & $2003(6)$ \\
\hline & $k=0$ & $k=1$ & $k=2$ & $k=3$ & $k=4$ \\
\hline BIC & 0.86 & -0.41 & $-0.56^{*}$ & -0.46 & -0.33 \\
\hline LWZ & 0.96 & -0.19 & $-0.21^{*}$ & 0.02 & 0.27 \\
\hline$S S R_{k}$ & & 82.73 & 62.28 & 60.61 & 60.46 \\
\hline UDMax & $75.03^{* * *}$ & & & & \\
\hline$F_{T}^{*}$ & & $75.03^{* * *}$ & $28.10^{* * *}$ & 17.89 & 13.09 \\
\hline$F_{T}^{*}(k+1 \mid k)$ & & $34.28^{* * *}$ & 2.07 & 0.48 & 0.12 \\
\hline $\min \left(\Delta T_{i}\right)$ & & 65 & 31 & 24 & 24 \\
\hline
\end{tabular}

South Korea-Oman: $T=171 \quad \epsilon T=26 \quad \epsilon=0.152$

\begin{tabular}{|c|c|c|c|c|c|}
\hline & & & & & Break $_{k+1}$ \\
\hline$k=1$ & & & & $2010(8)$ & $2008(6)$ \\
\hline$k=2$ & & & $2008(6)$ & $2010(8)$ & $2006(2)$ \\
\hline$k=3$ & & $2005(6)$ & $2007(8)$ & $2010(8)$ & 2003(3) \\
\hline \multirow[t]{2}{*}{$k=4$} & $2003(11)$ & $2006(2)$ & $2008(6)$ & $2010(8)$ & - \\
\hline & $k=0$ & $k=1$ & $k=2$ & $k=3$ & $k=4$ \\
\hline $\mathrm{BIC}$ & $-1.03^{*}$ & -0.94 & -0.96 & -0.92 & -0.79 \\
\hline LWZ & $-0.85^{*}$ & -0.54 & -0.35 & -0.09 & 0.26 \\
\hline$S S R_{k}$ & & 45.37 & 35.75 & 30.24 & 27.88 \\
\hline UDMax & 10.48 & & & & \\
\hline$F_{T}^{*}$ & & 8.05 & 10.48 & 10.16 & 7.74 \\
\hline$F_{T}^{*}(k+1 \mid k)$ & & 18.21 & 10.92 & 3.21 & 0.00 \\
\hline $\min \left(\Delta T_{i}\right)$ & & 46 & 26 & 26 & 26 \\
\hline
\end{tabular}

South Korea-Malaysia: $T=130 \quad \epsilon T=20 \quad \epsilon=0.154$

\begin{tabular}{|c|c|c|c|c|c|}
\hline & & & & & Break $_{k+1}$ \\
\hline$k=1$ & & & & $2012(4)$ & $2008(12)$ \\
\hline$k=2$ & & $2008(12)$ & & $2012(4)$ & $2010(8)$ \\
\hline$k=3$ & & $2008(12)$ & 2011(2) & 2012(10) & $2006(11)$ \\
\hline \multirow[t]{2}{*}{$k=4$} & $2006(11)$ & $2008(12)$ & $2011(2)$ & $2012(10)$ & - \\
\hline & $k=0$ & $k=1$ & $k=2$ & $k=3$ & $k=4$ \\
\hline BIC & 1.77 & $1.48^{*}$ & 1.57 & 1.65 & 1.83 \\
\hline LWZ & 1.90 & $1.79^{*}$ & 2.05 & 2.31 & 2.67 \\
\hline$S S R_{k}$ & & 408.54 & 369.99 & 332.46 & 330.71 \\
\hline UDMax & $12.90^{* *}$ & & & & \\
\hline$F_{T}^{*}$ & & $12.90^{* *}$ & 7.47 & 5.25 & 3.82 \\
\hline$F_{T}^{*}(k+1 \mid k)$ & & 3.93 & 1.80 & 0.22 & -0.00 \\
\hline $\min \left(\Delta T_{i}\right)$ & & 26 & 26 & 20 & 20 \\
\hline
\end{tabular}

South Korea-Qatar: $T=178 \quad \epsilon T=27 \quad \epsilon=0.152$

\begin{tabular}{|c|c|c|c|c|c|}
\hline & & & & & Break $_{k+1}$ \\
\hline$k=1$ & & & 2009(1) & & 2011(8) \\
\hline$k=2$ & & & $2008(3)$ & $2011(8)$ & $2005(12)$ \\
\hline$k=3$ & & 2006(1) & $2008(4)$ & $2011(8)$ & $2003(7)$ \\
\hline \multirow[t]{2}{*}{$k=4$} & $2003(7)$ & $2006(2)$ & $2008(5)$ & 2011(8) & - \\
\hline & $k=0$ & $k=1$ & $k=2$ & $k=3$ & $k=4$ \\
\hline BIC & $-1.50^{*}$ & -1.39 & -1.28 & -1.10 & -0.91 \\
\hline LWZ & $-1.26^{*}$ & -0.88 & -0.50 & -0.03 & 0.44 \\
\hline$S S R_{k}$ & & 26.97 & 23.22 & 21.49 & 20.00 \\
\hline UDMax & $10.80^{*}$ & & & & \\
\hline$F_{T}^{*}$ & & $10.80^{*}$ & 8.76 & 6.34 & 5.18 \\
\hline$F_{T}^{*}(k+1 \mid k)$ & & 9.13 & 6.24 & 5.78 & -0.00 \\
\hline $\min \left(\Delta T_{i}\right)$ & & 65 & 34 & 27 & 27 \\
\hline
\end{tabular}


Table 5: Break tests (Spain and Taiwan)

\begin{tabular}{|c|c|c|c|c|c|}
\hline \multicolumn{6}{|c|}{ Spain-Algeria: $T=233$} \\
\hline & & & & & Break $_{k+1}$ \\
\hline$k=1$ & & & $2007(1)$ & & $2011(6)$ \\
\hline$k=2$ & & & $2007(1)$ & $2011(6)$ & $2000(5)$ \\
\hline$k=3$ & & $2005(1)$ & $2007(12)$ & $2011(6)$ & $2000(5)$ \\
\hline \multirow{2}{*}{$k=4$} & $2000(5)$ & $2005(1)$ & $2007(12)$ & $2011(6)$ & - \\
\hline & $k=0$ & $k=1$ & $k=2$ & $k=3$ & $k=4$ \\
\hline BIC & -0.47 & -0.55 & $-0.59^{*}$ & -0.55 & -0.43 \\
\hline LWZ & $-0.32^{*}$ & -0.21 & -0.07 & 0.16 & 0.47 \\
\hline$S S R_{k}$ & & 99.01 & 80.64 & 71.26 & 68.40 \\
\hline UDMax & $19.72^{* * *}$ & & & & \\
\hline$F_{T}^{*}$ & & $19.72^{\text {*** }}$ & $16.51^{* * *}$ & 15.09 & 12.00 \\
\hline$F_{T}^{*}(k+1 \mid k)$ & & $22.67^{* * *}$ & 5.57 & 6.64 & 0.00 \\
\hline $\min \left(\Delta T_{i}\right)$ & & 88 & 35 & 35 & 35 \\
\hline
\end{tabular}

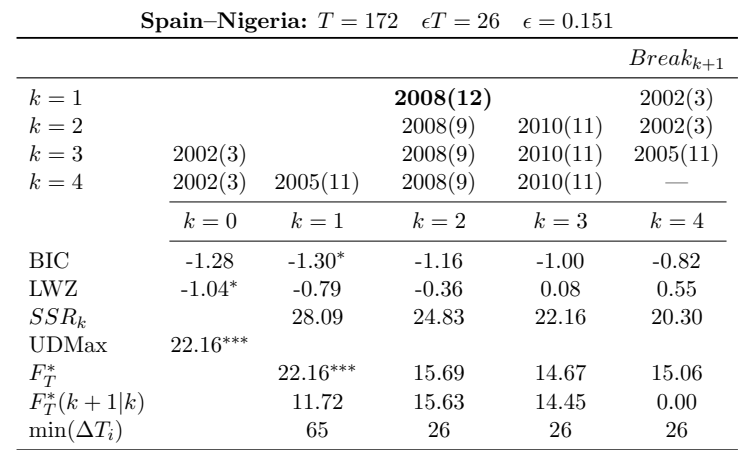

Spain-Qatar: $T=134 \quad \epsilon T=21 \quad \epsilon=0.157$

Taiwan-Indonesia: $T=173 \quad \epsilon T=26 \quad \epsilon=0.15$

\begin{tabular}{|c|c|c|c|c|c|}
\hline & & & & & Break $_{k+1}$ \\
\hline$k=1$ & & $2008(12)$ & & & $2012(8)$ \\
\hline$k=2$ & & $2008(12)$ & & 2012(8) & 2010(9) \\
\hline$k=3$ & & $2008(12)$ & $2010(9)$ & $2012(8)$ & $2006(2)$ \\
\hline \multirow[t]{2}{*}{$k=4$} & $2006(2)$ & $2008(12)$ & $2010(9)$ & $2012(8)$ & - \\
\hline & $k=0$ & $k=1$ & $k=2$ & $k=3$ & $k=4$ \\
\hline BIC & $-0.78^{*}$ & -0.69 & -0.62 & -0.36 & -0.08 \\
\hline LWZ & $-0.51^{*}$ & -0.11 & 0.27 & 0.86 & 1.47 \\
\hline$S S R_{k}$ & & 36.07 & 27.78 & 25.99 & 24.77 \\
\hline UDMax & $10.73^{*}$ & & & & \\
\hline$F_{T}^{*}$ & & $10.70^{*}$ & $10.73^{* *}$ & 7.65 & 5.88 \\
\hline$F_{T}^{*}(k+1 \mid k)$ & & $14.96^{* *}$ & 5.68 & 4.49 & -0.00 \\
\hline $\min \left(\Delta T_{i}\right)$ & & 65 & 21 & 21 & 21 \\
\hline
\end{tabular}

\begin{tabular}{|c|c|c|c|c|c|}
\hline & & & & & Break $_{k+1}$ \\
\hline$k=1$ & & & $2008(10)$ & & $2011(4)$ \\
\hline$k=2$ & & & $2008(10)$ & $2011(4)$ & $2006(8)$ \\
\hline$k=3$ & & $2006(8)$ & $2008(10)$ & 2011(4) & 2002(10) \\
\hline \multirow[t]{2}{*}{$k=4$} & $2002(10)$ & $2006(8)$ & $2008(10)$ & 2011(4) & - \\
\hline & $k=0$ & $k=1$ & $k=2$ & $k=3$ & $k=4$ \\
\hline BIC & -0.99 & $-0.99^{*}$ & -0.89 & -0.79 & -0.67 \\
\hline LWZ & $-0.90^{*}$ & -0.78 & -0.56 & -0.33 & -0.09 \\
\hline$S S R_{k}$ & & 52.04 & 51.10 & 50.35 & 50.20 \\
\hline UDMax & $17.30^{* * *}$ & & & & \\
\hline$F_{T}^{*}$ & & $17.30^{* * * *}$ & 9.59 & 6.98 & 5.22 \\
\hline$F_{T}^{*}(k+1 \mid k)$ & & 2.86 & 2.37 & 0.47 & 0.00 \\
\hline $\min \left(\Delta T_{i}\right)$ & & 67 & 30 & 26 & 26 \\
\hline
\end{tabular}

Taiwan-Malaysia: $T=112 \quad \epsilon T=28 \quad \epsilon=0.25$

\begin{tabular}{|c|c|c|c|c|c|}
\hline & & & & & Break $_{k+1}$ \\
\hline$k=1$ & $2008(12)$ & & & & $2011(11)$ \\
\hline \multirow[t]{2}{*}{$k=2$} & $2008(11)$ & $2011(6)$ & & & - \\
\hline & $k=0$ & $k=1$ & $k=2$ & $k=3$ & $k=4$ \\
\hline BIC & 2.06 & $1.57^{*}$ & 1.59 & & \\
\hline LWZ & 2.28 & $2.05^{*}$ & 2.34 & & \\
\hline$S S R_{k}$ & & 311.35 & 237.20 & & \\
\hline UDMax & $49.37^{* * *}$ & & & & \\
\hline$F_{T}^{*}$ & & $49.37^{* * *}$ & 21.70 & & \\
\hline$F_{T}^{*}(k+1 \mid k)$ & & 6.93 & -0.00 & & \\
\hline $\min \left(\Delta T_{i}\right)$ & & 47 & 31 & & \\
\hline
\end{tabular}


Table 6: Estimates for average Japanese LNG pricing terms (I)

\begin{tabular}{|c|c|c|c|c|c|c|c|c|c|c|c|}
\hline \multirow[b]{2}{*}{ Start } & \multicolumn{3}{|c|}{ Japan-Australia } & \multicolumn{2}{|c|}{ Japan-Brunei } & \multicolumn{3}{|c|}{ Japan-Indonesia } & \multicolumn{3}{|c|}{ Japan-Malaysia } \\
\hline & $1989(08)$ & $2005(04)$ & $2009(01)$ & $1988(08)$ & $2008(01)$ & 1988(04) & $2005(01)$ & $2011(04)$ & $1988(05)$ & $2004(10)$ & $2008(10)$ \\
\hline End & $2005(03)$ & $2008(12)$ & $2014(06)$ & $2007(12)$ & $2014(06)$ & $2004(12)$ & $2011(03)$ & $2014(06)$ & 2004(09) & 2008(09) & $2014(06)$ \\
\hline$c$ & $\begin{array}{c}1.869^{* * *} \\
(0.128)\end{array}$ & $\begin{array}{c}0.078 \\
(0.533)\end{array}$ & $\begin{array}{c}1.218 \\
(0.656)\end{array}$ & $\begin{array}{c}2.309^{* * *} \\
(0.149)\end{array}$ & $\begin{array}{c}-0.429 \\
(1.502)\end{array}$ & $\begin{array}{c}0.951^{\text {*** }} \\
(0.118)\end{array}$ & $\begin{array}{c}2.337^{* * *} \\
(0.176)\end{array}$ & $\begin{array}{c}-3.352 \\
(2.483)\end{array}$ & $\begin{array}{c}1.247^{* * *} \\
(0.098)\end{array}$ & $\begin{array}{c}0.674 \\
(0.715)\end{array}$ & $\begin{array}{r}-1.156^{*} \\
(0.438)\end{array}$ \\
\hline$\delta$ & $\begin{array}{c}0.095^{* * *} \\
(0.006)\end{array}$ & $\begin{array}{c}0.108^{* * *} \\
(0.007)\end{array}$ & $\begin{array}{l}0.129^{* * *} \\
(0.007)\end{array}$ & $\begin{array}{l}0.064^{* * *} \\
(0.005)\end{array}$ & $\begin{array}{l}0.156^{* * *} \\
(0.015)\end{array}$ & $\begin{array}{l}0.141^{* * *} \\
(0.005)\end{array}$ & $\begin{array}{l}0.089^{* * *} \\
(0.002)\end{array}$ & $\begin{array}{l}0.188^{* * *} \\
(0.022)\end{array}$ & $\begin{array}{l}0.120^{* * *} \\
(0.005)\end{array}$ & $\begin{array}{l}0.101^{* * *} \\
(0.012)\end{array}$ & $\begin{array}{c}0.166^{\text {*** }} \\
(0.004)\end{array}$ \\
\hline$\theta_{0}$ & $\begin{array}{c}-0.189 \\
(0.256)\end{array}$ & $\begin{array}{c}0.095 \\
(0.257)\end{array}$ & $\begin{array}{c}0.041 \\
(0.238)\end{array}$ & $\begin{array}{c}0.296 \\
(0.623)\end{array}$ & $\begin{array}{c}0.055 \\
(0.337)\end{array}$ & $\begin{array}{c}0.993^{* * *} \\
(0.160)\end{array}$ & $\begin{array}{l}0.932^{* * *} \\
(0.093)\end{array}$ & $\begin{array}{c}0.342^{* *} \\
(0.106)\end{array}$ & $\begin{array}{c}0.050 \\
(0.150)\end{array}$ & $\begin{array}{c}0.439 \\
(0.474)\end{array}$ & $\begin{array}{c}0.338^{* *} \\
(0.101)\end{array}$ \\
\hline$\theta_{1}$ & $\begin{array}{c}-0.034 \\
(0.453)\end{array}$ & $\begin{array}{r}-0.324 \\
(0.505)\end{array}$ & $\begin{array}{c}0.084 \\
(0.373)\end{array}$ & $\begin{array}{r}-0.145 \\
(1.066)\end{array}$ & $\begin{array}{c}0.134 \\
(0.612)\end{array}$ & $\begin{array}{c}0.075 \\
(0.288)\end{array}$ & $\begin{array}{c}0.147 \\
(0.175)\end{array}$ & $\begin{array}{c}0.013 \\
(0.169)\end{array}$ & $\begin{array}{r}-0.102 \\
(0.277)\end{array}$ & $\begin{array}{c}0.070 \\
(0.845)\end{array}$ & $\begin{array}{r}-0.111 \\
(0.181)\end{array}$ \\
\hline$\theta_{2}$ & $\begin{array}{c}0.242 \\
(0.476)\end{array}$ & $\begin{array}{c}0.375 \\
(0.592)\end{array}$ & $\begin{array}{c}0.107 \\
(0.364)\end{array}$ & $\begin{array}{c}-0.283 \\
(1.108)\end{array}$ & $\begin{array}{c}0.044 \\
(0.612)\end{array}$ & $\begin{array}{r}-0.085 \\
(0.293)\end{array}$ & $\begin{array}{r}-0.092 \\
(0.174)\end{array}$ & $\begin{array}{c}-0.094 \\
(0.168)\end{array}$ & $\begin{array}{c}0.161 \\
(0.296)\end{array}$ & $\begin{array}{c}0.093 \\
(0.910)\end{array}$ & $\begin{array}{r}-0.056 \\
(0.178)\end{array}$ \\
\hline$\theta_{3}$ & $\begin{array}{c}0.845 \\
(0.465)\end{array}$ & $\begin{array}{c}0.816 \\
(0.621)\end{array}$ & $\begin{array}{c}0.625 \\
(0.340)\end{array}$ & $\begin{array}{c}0.409 \\
(1.109)\end{array}$ & $\begin{array}{r}-0.014 \\
(0.632)\end{array}$ & $\begin{array}{c}0.017 \\
(0.168)\end{array}$ & $\begin{array}{c}0.013 \\
(0.099)\end{array}$ & $\begin{array}{c}0.739^{* * *} \\
(0.108)\end{array}$ & $\begin{array}{c}-0.014 \\
(0.279)\end{array}$ & $\begin{array}{c}0.711 \\
(0.920)\end{array}$ & $\begin{array}{r}0.466^{*} \\
(0.178)\end{array}$ \\
\hline$\theta_{4}$ & $\begin{array}{c}0.136 \\
(0.262)\end{array}$ & $\begin{array}{c}0.037 \\
(0.377)\end{array}$ & $\begin{array}{c}0.142 \\
(0.186)\end{array}$ & $\begin{array}{c}0.655 \\
(1.140)\end{array}$ & $\begin{array}{c}0.518 \\
(0.627)\end{array}$ & & & & $\begin{array}{c}0.905^{* * *} \\
(0.152)\end{array}$ & $\begin{array}{c}-0.313 \\
(0.630)\end{array}$ & $\begin{array}{c}0.363^{* * *} \\
(0.096)\end{array}$ \\
\hline$\theta_{5}$ & & & & $\begin{array}{c}0.160 \\
(1.159)\end{array}$ & $\begin{array}{c}-0.171 \\
(0.603)\end{array}$ & & & & & & \\
\hline$\theta_{6}$ & & & & $\begin{array}{c}0.689 \\
(1.123)\end{array}$ & $\begin{array}{c}-0.094 \\
(0.604)\end{array}$ & & & & & & \\
\hline$\theta_{7}$ & & & & $\begin{array}{r}-0.781 \\
(0.685)\end{array}$ & $\begin{array}{c}0.528 \\
(0.327)\end{array}$ & & & & & & \\
\hline$T$ & 188 & 45 & 66 & 233 & 78 & 201 & 75 & 39 & 197 & 48 & 69 \\
\hline$\hat{\sigma}_{i}$ & 0.174 & 0.576 & 0.664 & 0.338 & 1.060 & 0.152 & 0.287 & 0.463 & 0.161 & 0.607 & 0.548 \\
\hline$\hat{\sigma}_{L R, i}$ & 0.469 & 0.922 & 1.086 & 1.063 & 2.413 & 0.440 & 0.376 & 0.499 & 0.335 & 1.277 & 0.735 \\
\hline$\hat{\rho}_{i}$ & 0.797 & 0.538 & 0.467 & 0.801 & 0.757 & 0.812 & 0.363 & 0.217 & 0.690 & 0.662 & 0.445 \\
\hline $\mathrm{DW}_{i}$ & 0.370 & 0.926 & 1.065 & 0.361 & 0.501 & 0.387 & 1.210 & 1.520 & 0.613 & 0.587 & 1.090 \\
\hline $\operatorname{Pr}\left(\mathrm{DW}_{i}\right)$ & 0.000 & 0.000 & 0.000 & 0.000 & 0.000 & 0.000 & 0.000 & 0.047 & 0.000 & 0.000 & 0.000 \\
\hline$\hat{\sigma}$ & & 0.400 & & 0.5 & & & 0.242 & & & 0.364 & \\
\hline$\hat{\sigma}_{L R}$ & & 0.720 & & 1.5 & & & 0.372 & & & 0.611 & \\
\hline$\hat{\rho}$ & & 0.511 & & 0.7 & & & 0.384 & & & 0.452 & \\
\hline D-Fuller & & -9.778 & & -6 & & & -11.810 & & & -10.862 & \\
\hline
\end{tabular}


Table 7: Estimates for average Japanese LNG pricing terms (II)

\begin{tabular}{|c|c|c|c|c|c|c|c|c|c|c|c|}
\hline \multirow[b]{2}{*}{ Start } & \multicolumn{3}{|c|}{ Japan-Qatar } & \multicolumn{3}{|c|}{ Japan-U.A.E. } & \multicolumn{5}{|c|}{ Japan-U.S.A. } \\
\hline & $1997(01)$ & $2005(10)$ & $2009(05)$ & 1993(06) & $2005(01)$ & $2009(03)$ & $1988(04)$ & 1991(04) & $1999(12)$ & $2006(01)$ & $2009(04)$ \\
\hline End & 2005(09) & 2009(04) & $2014(06)$ & $2004(12)$ & 2009(02) & 2014(06) & 1991(03) & $1999(11)$ & $2005(12)$ & 2009(03) & 2011(03) \\
\hline$c$ & $\begin{array}{l}1.890^{* * *} \\
(0.211)\end{array}$ & $\begin{array}{c}-1.848^{* *} \\
(0.565)\end{array}$ & $\begin{array}{c}2.305^{* * *} \\
(0.308)\end{array}$ & $\begin{array}{l}1.335^{\text {*** }} \\
(0.251)\end{array}$ & $\begin{array}{c}0.485 \\
(0.321)\end{array}$ & $\begin{array}{c}-0.389 \\
(0.319)\end{array}$ & $\begin{array}{c}1.452^{* * *} \\
(0.131)\end{array}$ & $\begin{array}{c}0.974^{* * *} \\
(0.173)\end{array}$ & $\begin{array}{l}2.470^{* * *} \\
(0.059)\end{array}$ & $\begin{array}{l}3.447^{* * *} \\
(0.059)\end{array}$ & $\begin{array}{c}0.823^{* *} \\
(0.236)\end{array}$ \\
\hline$\delta$ & $\begin{array}{c}0.095^{* * *} \\
(0.008)\end{array}$ & $\begin{array}{c}0.156^{* * *} \\
(0.007)\end{array}$ & $\begin{array}{c}0.132^{* * *} \\
(0.003)\end{array}$ & $\begin{array}{l}0.113^{* * *} \\
(0.011)\end{array}$ & $\begin{array}{l}0.106^{* * *} \\
(0.004)\end{array}$ & $\begin{array}{c}0.155^{* * *} \\
(0.003)\end{array}$ & $\begin{array}{l}0.096^{* * *} \\
(0.007)\end{array}$ & $\begin{array}{c}0.134^{* * *} \\
(0.010)\end{array}$ & $\begin{array}{c}0.070^{* * *} \\
(0.002)\end{array}$ & $\begin{array}{l}0.041^{* * *} \\
(0.001)\end{array}$ & $\begin{array}{c}0.146^{* * *} \\
(0.003)\end{array}$ \\
\hline$\theta_{0}$ & $\begin{array}{c}-0.094 \\
(0.392)\end{array}$ & $\begin{array}{c}-0.027 \\
(0.161)\end{array}$ & $\begin{array}{c}0.029 \\
(0.097)\end{array}$ & $\begin{array}{c}0.072 \\
(0.442)\end{array}$ & $\begin{array}{c}-0.116 \\
(0.177)\end{array}$ & $\begin{array}{c}0.173 \\
(0.095)\end{array}$ & $\begin{array}{c}0.080 \\
(0.213)\end{array}$ & $\begin{array}{c}0.183 \\
(0.226)\end{array}$ & $\begin{array}{c}0.076 \\
(0.118)\end{array}$ & $\begin{array}{c}0.042 \\
(0.062)\end{array}$ & $\begin{array}{c}-0.015 \\
(0.063)\end{array}$ \\
\hline$\theta_{1}$ & $\begin{array}{c}0.038 \\
(0.642)\end{array}$ & $\begin{array}{c}0.103 \\
(0.310)\end{array}$ & $\begin{array}{r}-0.185 \\
(0.144)\end{array}$ & $\begin{array}{r}-0.121 \\
(0.720)\end{array}$ & $\begin{array}{c}-0.104 \\
(0.338)\end{array}$ & $\begin{array}{r}-0.242 \\
(0.145)\end{array}$ & $\begin{array}{c}0.287 \\
(0.474)\end{array}$ & $\begin{array}{r}-0.054 \\
(0.389)\end{array}$ & $\begin{array}{r}-0.060 \\
(0.188)\end{array}$ & $\begin{array}{c}-0.493^{* * *} \\
(0.116)\end{array}$ & $\begin{array}{r}-0.043 \\
(0.086)\end{array}$ \\
\hline$\theta_{2}$ & $\begin{array}{c}0.350 \\
(0.645)\end{array}$ & $\begin{array}{c}0.172 \\
(0.320)\end{array}$ & $\begin{array}{c}0.422^{* *} \\
(0.146)\end{array}$ & $\begin{array}{c}0.206 \\
(0.757)\end{array}$ & $\begin{array}{c}0.292 \\
(0.342)\end{array}$ & $\begin{array}{c}0.226 \\
(0.144)\end{array}$ & $\begin{array}{r}-1.038^{*} \\
(0.486)\end{array}$ & $\begin{array}{r}-0.746^{*} \\
(0.372)\end{array}$ & $\begin{array}{c}0.086 \\
(0.189)\end{array}$ & $\begin{array}{l}0.576^{* * *} \\
(0.120)\end{array}$ & $\begin{array}{c}0.088 \\
(0.087)\end{array}$ \\
\hline$\theta_{3}$ & $\begin{array}{c}0.267 \\
(0.645)\end{array}$ & $\begin{array}{c}0.116 \\
(0.336)\end{array}$ & $\begin{array}{c}0.452^{* *} \\
(0.144)\end{array}$ & $\begin{array}{c}-0.224 \\
(0.754)\end{array}$ & $\begin{array}{c}0.444 \\
(0.344)\end{array}$ & $\begin{array}{c}0.630^{* * *} \\
(0.142)\end{array}$ & $\begin{array}{l}1.671^{* * *} \\
(0.223)\end{array}$ & $\begin{array}{l}1.617^{\text {*** }} \\
(0.205)\end{array}$ & $\begin{array}{c}0.899^{* * *} \\
(0.122)\end{array}$ & $\begin{array}{l}0.875^{* * *} \\
(0.058)\end{array}$ & $\begin{array}{c}0.970^{* * *} \\
(0.065)\end{array}$ \\
\hline$\theta_{4}$ & $\begin{array}{c}0.214 \\
(0.669)\end{array}$ & $\begin{array}{c}0.213 \\
(0.333)\end{array}$ & $\begin{array}{c}0.170 \\
(0.142)\end{array}$ & $\begin{array}{c}1.066^{*} \\
(0.460)\end{array}$ & $\begin{array}{c}0.484^{*} \\
(0.184)\end{array}$ & $\begin{array}{c}0.212^{*} \\
(0.081)\end{array}$ & & & & & \\
\hline$\theta_{5}$ & $\begin{array}{c}0.110 \\
(0.676)\end{array}$ & $\begin{array}{r}-0.147 \\
(0.322)\end{array}$ & $\begin{array}{c}0.134 \\
(0.139)\end{array}$ & & & & & & & & \\
\hline$\theta_{6}$ & $\begin{array}{c}0.116 \\
(0.426)\end{array}$ & $\begin{array}{c}0.570^{* *} \\
(0.171)\end{array}$ & $\begin{array}{c}-0.021 \\
(0.080)\end{array}$ & & & & & & & & \\
\hline$T$ & 105 & 43 & 62 & 139 & 50 & 64 & 36 & 104 & 73 & 39 & 24 \\
\hline$\hat{\sigma}_{i}$ & 0.216 & 0.566 & 0.441 & 0.279 & 0.432 & 0.386 & 0.126 & 0.163 & 0.084 & 0.103 & 0.230 \\
\hline$\hat{\sigma}_{L R, i}$ & 0.625 & 0.812 & 0.416 & 0.788 & 0.619 & 0.504 & 0.157 & 0.247 & 0.133 & 0.085 & 0.179 \\
\hline$\hat{\rho}_{i}$ & 0.886 & 0.502 & 0.043 & 0.791 & 0.376 & 0.318 & 0.403 & 0.493 & 0.462 & -0.251 & -0.228 \\
\hline $\mathrm{DW}_{i}$ & 0.205 & 0.971 & 1.889 & 0.405 & 1.247 & 1.359 & 1.137 & 1.002 & 1.051 & 2.455 & 2.434 \\
\hline $\operatorname{Pr}\left(\mathrm{DW}_{i}\right)$ & 0.000 & 0.000 & 0.271 & 0.000 & 0.001 & 0.003 & 0.001 & 0.000 & 0.000 & 0.870 & 0.795 \\
\hline$\hat{\sigma}$ & & 0.376 & & & 0.340 & & & & 0.141 & & \\
\hline$\hat{\sigma}_{L R}$ & & 0.540 & & & 0.627 & & & & 0.180 & & \\
\hline$\hat{\rho}$ & & 0.391 & & & 0.511 & & & & 0.284 & & \\
\hline D-Fuller & & -9.464 & & & -8.983 & & & & -12.341 & & \\
\hline
\end{tabular}

${ }^{* * *} p<0.001,{ }^{* *} p<0.01,{ }^{*} p<0.05$ Standard errors in parenthesis are calculated by the delta-method. DW is the Durbin-Watson test for first-order autocorrelation. 
Table 8: Estimates for average South Korean LNG pricing terms

\begin{tabular}{|c|c|c|c|c|c|c|c|}
\hline \multirow[b]{2}{*}{ Start } & \multicolumn{3}{|c|}{ South Korea-Indonesia } & \multicolumn{2}{|c|}{ South Korea-Malaysia } & \multirow{2}{*}{$\frac{\text { South Korea-Oman }}{2000(04)}$} & \multirow{2}{*}{$\frac{\text { South Korea-Qatar }}{1999(09)}$} \\
\hline & $2001(07)$ & $2009(01)$ & $2011(08)$ & 2003(09) & $2012(05)$ & & \\
\hline End & $2008(12)$ & 2011(07) & $2014(06)$ & $2012(04)$ & $2014(06)$ & $2014(06)$ & $2014(06)$ \\
\hline$c$ & $\begin{array}{l}0.738^{* * *} \\
(0.069)\end{array}$ & $\begin{array}{l}3.951^{* * *} \\
(0.625)\end{array}$ & $\begin{array}{l}13.192^{* * *} \\
(2.794)\end{array}$ & $\begin{array}{l}2.958^{* * *} \\
(0.409)\end{array}$ & $\begin{array}{c}-36.246 \\
(45.232)\end{array}$ & $\begin{array}{l}0.719^{* * *} \\
(0.139)\end{array}$ & $\begin{array}{l}0.817^{* * *} \\
(0.098)\end{array}$ \\
\hline$\delta$ & $\begin{array}{l}0.157^{* * *} \\
(0.001)\end{array}$ & $\begin{array}{l}0.077^{* * *} \\
(0.008)\end{array}$ & $\begin{array}{c}0.006 \\
(0.025)\end{array}$ & $\begin{array}{l}0.065^{* * *} \\
(0.005)\end{array}$ & $\begin{array}{c}0.452 \\
(0.408)\end{array}$ & $\begin{array}{l}0.156^{* * *} \\
(0.002)\end{array}$ & $\begin{array}{l}0.154^{* * *} \\
(0.001)\end{array}$ \\
\hline$\theta_{0}$ & $\begin{array}{r}-0.086^{*} \\
(0.033)\end{array}$ & $\begin{array}{c}0.309 \\
(0.423)\end{array}$ & $\begin{array}{l}-11.460 \\
(53.175)\end{array}$ & $\begin{array}{c}0.466 \\
(0.466)\end{array}$ & $\begin{array}{c}0.568 \\
(0.762)\end{array}$ & $\begin{array}{c}-0.082 \\
(0.097)\end{array}$ & $\begin{array}{c}-0.078 \\
(0.072)\end{array}$ \\
\hline$\theta_{1}$ & $\begin{array}{l}1.086^{* * *} \\
(0.033)\end{array}$ & $\begin{array}{c}0.691 \\
(0.423)\end{array}$ & $\begin{array}{c}12.460 \\
(53.175)\end{array}$ & $\begin{array}{c}-1.412 \\
(0.831)\end{array}$ & $\begin{array}{r}-0.317 \\
(1.045)\end{array}$ & $\begin{array}{c}0.020 \\
(0.175)\end{array}$ & $\begin{array}{c}0.077 \\
(0.131)\end{array}$ \\
\hline$\theta_{2}$ & & & & $\begin{array}{l}1.946^{* * *} \\
(0.474)\end{array}$ & $\begin{array}{c}0.749 \\
(0.628)\end{array}$ & $\begin{array}{c}0.072 \\
(0.177)\end{array}$ & $\begin{array}{c}0.092 \\
(0.134)\end{array}$ \\
\hline$\theta_{3}$ & & & & & & $\begin{array}{l}0.583^{* *} \\
(0.175)\end{array}$ & $\begin{array}{c}0.080 \\
(0.135)\end{array}$ \\
\hline$\theta_{4}$ & & & & & & $\begin{array}{l}0.407^{* * *} \\
(0.096)\end{array}$ & $\begin{array}{l}0.374^{* *} \\
(0.134)\end{array}$ \\
\hline$\theta_{5}$ & & & & & & & $\begin{array}{r}0.334^{*} \\
(0.131)\end{array}$ \\
\hline$\theta_{6}$ & & & & & & & $\begin{array}{c}0.122 \\
(0.072)\end{array}$ \\
\hline$T$ & 90 & 31 & 35 & 104 & 26 & 171 & 178 \\
\hline$\hat{\sigma}_{i}$ & 0.310 & 1.001 & 0.899 & 1.281 & 3.333 & 0.557 & 0.431 \\
\hline$\hat{\sigma}_{L R, i}$ & 0.303 & 0.889 & 0.703 & 1.472 & 6.769 & 0.816 & 0.604 \\
\hline$\hat{\rho}_{i}$ & -0.027 & -0.095 & -0.263 & 0.181 & 0.658 & 0.413 & 0.552 \\
\hline $\mathrm{DW}_{i}$ & 2.049 & 2.181 & 2.472 & 1.639 & 0.627 & 1.171 & 0.891 \\
\hline $\operatorname{Pr}\left(\mathrm{DW}_{i}\right)$ & 0.526 & 0.624 & 0.891 & 0.022 & 0.000 & 0.000 & 0.000 \\
\hline$\hat{\sigma}$ & & 0.651 & & 1.8 & & 0.557 & 0.431 \\
\hline$\hat{\sigma}_{L R}$ & & 0.579 & & 3.1 & & 0.816 & 0.604 \\
\hline$\hat{\rho}$ & & -0.149 & & 0.4 & & 0.413 & 0.552 \\
\hline D-Fuller & & -14.275 & & -6. & & -8.332 & -7.041 \\
\hline
\end{tabular}

${ }^{* *} p<0.001,{ }^{* *} p<0.01,{ }^{*} p<0.05$ Standard errors in parenthesis are calculated by the delta-method.

DW is the Durbin-Watson test for first-order autocorrelation. 
Table 9: Estimates for average Spanish and Taiwanese LNG pricing terms

\begin{tabular}{|c|c|c|c|c|c|c|c|c|c|c|}
\hline \multirow[b]{2}{*}{ Start } & \multicolumn{3}{|c|}{ Spain-Algeria } & \multicolumn{2}{|c|}{ Spain-Nigeria } & \multirow{2}{*}{$\frac{\text { Spain-Qatar }}{2003(04)}$} & \multicolumn{2}{|c|}{ Taiwan-Indonesia } & \multicolumn{2}{|c|}{ Taiwan-Malaysia } \\
\hline & $1995(01)$ & $2007(02)$ & $2011(07)$ & $2000(02)$ & $2009(01)$ & & $2000(01)$ & $2008(11)$ & $2005(02)$ & $2009(01)$ \\
\hline End & $2007(01)$ & $2011(06)$ & $2014(05)$ & $2008(12)$ & $2014(05)$ & 2014(05) & $2008(10)$ & 2014(05) & $2008(12)$ & $2014(05)$ \\
\hline$c$ & $\begin{array}{l}0.942^{* * *} \\
(0.098)\end{array}$ & $\begin{array}{c}2.859^{* *} \\
(0.993)\end{array}$ & $\begin{array}{l}12.409^{* *} \\
(4.281)\end{array}$ & $\begin{array}{l}1.082^{\text {*** }} \\
(0.140)\end{array}$ & $\begin{array}{l}2.109^{* * *} \\
(0.306)\end{array}$ & $\begin{array}{l}1.360^{* * *} \\
(0.215)\end{array}$ & $\begin{array}{l}1.008^{* * *} \\
(0.118)\end{array}$ & $\begin{array}{c}0.907^{* *} \\
(0.287)\end{array}$ & $\begin{array}{c}-0.260 \\
(0.981)\end{array}$ & $\begin{array}{c}-1.673 \\
(0.960)\end{array}$ \\
\hline$\delta$ & $\begin{array}{l}0.090^{* * *} \\
(0.003)\end{array}$ & $\begin{array}{l}0.073^{* * *} \\
(0.012)\end{array}$ & $\begin{array}{c}-0.014 \\
(0.039)\end{array}$ & $\begin{array}{l}0.083^{* * *} \\
(0.003)\end{array}$ & $\begin{array}{l}0.068^{* * *} \\
(0.003)\end{array}$ & $\begin{array}{l}0.080^{* * *} \\
(0.003)\end{array}$ & $\begin{array}{l}0.152^{* * *} \\
(0.002)\end{array}$ & $\begin{array}{l}0.158^{* * *} \\
(0.003)\end{array}$ & $\begin{array}{l}0.131^{* * *} \\
(0.014)\end{array}$ & $\begin{array}{l}0.173^{* * *} \\
(0.010)\end{array}$ \\
\hline$\theta_{0}$ & $\begin{array}{c}-0.034 \\
(0.184)\end{array}$ & $\begin{array}{c}0.375 \\
(0.449)\end{array}$ & $\begin{array}{c}3.949 \\
(9.938)\end{array}$ & $\begin{array}{c}0.419^{*} \\
(0.202)\end{array}$ & $\begin{array}{l}0.889^{* * *} \\
(0.191)\end{array}$ & $\begin{array}{c}0.179 \\
(0.208)\end{array}$ & $\begin{array}{c}0.162^{*} \\
(0.070)\end{array}$ & $\begin{array}{c}-0.130 \\
(0.072)\end{array}$ & $\begin{array}{c}0.524 \\
(0.397)\end{array}$ & $\begin{array}{c}0.268 \\
(0.257)\end{array}$ \\
\hline$\theta_{1}$ & $\begin{array}{c}0.078 \\
(0.267)\end{array}$ & $\begin{array}{c}0.084 \\
(0.765)\end{array}$ & $\begin{array}{c}0.603 \\
(3.074)\end{array}$ & $\begin{array}{c}-0.466 \\
(0.390)\end{array}$ & $\begin{array}{r}-0.710^{*} \\
(0.310)\end{array}$ & $\begin{array}{c}-0.218 \\
(0.377)\end{array}$ & $\begin{array}{l}0.838^{* * *} \\
(0.070)\end{array}$ & $\begin{array}{l}1.130^{* * *} \\
(0.072)\end{array}$ & $\begin{array}{c}-2.802^{* *} \\
(0.843)\end{array}$ & $\begin{array}{c}-0.327 \\
(0.406)\end{array}$ \\
\hline$\theta_{2}$ & $\begin{array}{c}-0.003 \\
(0.274)\end{array}$ & $\begin{array}{r}-0.654 \\
(0.729)\end{array}$ & $\begin{array}{l}-7.387 \\
(21.007)\end{array}$ & $\begin{array}{r}-0.012 \\
(0.440)\end{array}$ & $\begin{array}{c}0.086 \\
(0.309)\end{array}$ & $\begin{array}{c}0.521 \\
(0.387)\end{array}$ & & & $\begin{array}{r}2.194^{*} \\
(0.994)\end{array}$ & $\begin{array}{c}0.797 \\
(0.402)\end{array}$ \\
\hline$\theta_{3}$ & $\begin{array}{c}0.184 \\
(0.276)\end{array}$ & $\begin{array}{c}-0.226 \\
(0.783)\end{array}$ & $\begin{array}{c}6.266 \\
(17.135)\end{array}$ & $\begin{array}{c}0.314 \\
(0.465)\end{array}$ & $\begin{array}{c}0.317 \\
(0.292)\end{array}$ & $\begin{array}{c}0.112 \\
(0.391)\end{array}$ & & & $\begin{array}{r}-0.842 \\
(0.961)\end{array}$ & $\begin{array}{r}-0.019 \\
(0.367)\end{array}$ \\
\hline$\theta_{4}$ & $\begin{array}{l}0.775^{* * *} \\
(0.192)\end{array}$ & $\begin{array}{l}1.420^{* *} \\
(0.446)\end{array}$ & $\begin{array}{r}-2.431 \\
(7.633)\end{array}$ & $\begin{array}{c}0.266 \\
(0.472)\end{array}$ & $\begin{array}{c}0.259 \\
(0.288)\end{array}$ & $\begin{array}{c}0.087 \\
(0.386)\end{array}$ & & & $\begin{array}{l}1.927^{* *} \\
(0.556)\end{array}$ & $\begin{array}{c}0.281 \\
(0.201)\end{array}$ \\
\hline$\theta_{5}$ & & & & $\begin{array}{c}0.108 \\
(0.468)\end{array}$ & $\begin{array}{r}-0.273 \\
(0.281)\end{array}$ & $\begin{array}{c}0.008 \\
(0.378)\end{array}$ & & & & \\
\hline$\theta_{6}$ & & & & $\begin{array}{c}0.371 \\
(0.304)\end{array}$ & $\begin{array}{c}0.434^{* *} \\
(0.152)\end{array}$ & $\begin{array}{c}0.311 \\
(0.207)\end{array}$ & & & & \\
\hline$T$ & 145 & 53 & 35 & 107 & 65 & 134 & 106 & 67 & 47 & 65 \\
\hline$\hat{\sigma}_{i}$ & 0.331 & 0.977 & 0.842 & 0.367 & 0.509 & 0.602 & 0.556 & 0.561 & 1.985 & 1.594 \\
\hline$\hat{\sigma}_{L R, i}$ & 0.549 & 1.492 & 0.664 & 0.627 & 0.471 & 0.883 & 0.588 & 0.546 & 1.783 & 1.587 \\
\hline$\hat{\rho}_{i}$ & 0.413 & 0.518 & -0.236 & 0.549 & -0.059 & 0.382 & 0.113 & -0.031 & -0.084 & 0.094 \\
\hline $\mathrm{DW}_{i}$ & 1.165 & 0.961 & 2.455 & 0.899 & 2.110 & 1.224 & 1.771 & 1.768 & 1.849 & 1.805 \\
\hline $\operatorname{Pr}\left(\mathrm{DW}_{i}\right)$ & 0.000 & 0.000 & 0.869 & 0.000 & 0.592 & 0.000 & 0.091 & 0.131 & 0.223 & 0.168 \\
\hline$\hat{\sigma}$ & & 0.612 & & & & 0.602 & & & & \\
\hline$\hat{\sigma}_{L R}$ & & 0.828 & & & & 0.883 & 0.5 & & & \\
\hline$\hat{\rho}$ & & 0.307 & & 0.2 & & 0.382 & 0.0 & & 0.0 & \\
\hline D-Fuller & & -10.983 & & -10 & & -7.527 & -12 & & -10 & \\
\hline
\end{tabular}

${ }^{* * *} p<0.001,{ }^{* *} p<0.01,{ }^{*} p<0.05$ Standard errors in parenthesis are calculated by the delta-method. DW is the Durbin-Watson test for first-order autocorrelation 


\section{References}

Andrews, D. W. (1991). Heteroskedasticity and autocorrelation consistent covariance matrix estimation. Econometrica 59(3), 817-858.

Bai, J. and P. Perron (1998). Estimating and testing linear models with multiple structural changes. Econometrica 66(1), 47-78.

Bai, J. and P. Perron (2003). Computation and analysis of multiple structural change models. Journal of Applied Econometrics 18(1), 1-22.

Brigida, M. (2014). The switching relationship between natural gas and crude oil prices. Energy Economics 43, 48-55.

Brito, D. L. and P. R. Hartley (2007). Expectations and the evolving world gas market. The Energy Journal 28(1), 1-24.

Brown, S. P. and M. K. Yücel (2008). What drives natural gas prices? The Energy Journal 28(2), 45-60.

Brown, S. P. and M. K. Yücel (2009). Market arbitrage:European and North American natural gas prices. The Energy Journal 30(Special Issue), 167-185.

De Vany, A. and W. D. Walls (1993). Pipeline access and market integration in the natural gas industry: Evidence from cointegration tests. The Energy Journal 14(4), 1-19.

Engle, R. F. and C. W. Granger (1987). Co-integration and error correction: representation, estimation, and testing. Econometrica 55(2), 251-276.

Ernst \& Young (2013). Global LNG: Will new demand and new supply mean new pricing? http://www.ey.com/Publication/vwLUAssets/Global_LNG_New_pricing_ahead/ \$FILE/Global_LNG_New_pricing_ahead_DW0240.pdf.

Flower, A. (2011). LNG in Qatar. In B. Fattouh and J. P. Stern (Eds.), Natural gas markets in the Middle East and North Africa. Oxford University Press.

Ghoshray, A. (2014). How persistent are shocks to oil prices? In Online Proceedings of 37th IAEE International Conference.

Gregory, A. W. and B. E. Hansen (1996). Residual-based tests for cointegration in models with regime shifts. Journal of Econometrics 70(1), 99-126.

Hartley, P. R. (2015). The future of long-term LNG contracts. The Energy Journal 36(3), 209-233.

Hartley, P. R., A. M. Jaffe, and K. B. Medlock, III (2007). International influences on the link between U.S. crude oil and natural gas prices. Policy report, The James A. Baker III Institute for Public Policy, Rice University. 
Hartley, P. R. and K. B. Medlock, III (2014). The relationship between crude oil and natural gas prices: The role of the exchange rate. The Energy Journal 35(2), 25-44.

Hartley, P. R., K. B. Medlock, III, and J. E. Rosthal (2008). The relationship of natural gas to oil prices. The Energy Journal 29(3), 47-65.

Ikonnikova, S., D. Volkov, G. Gulen, C. BEG, and M. Foss (2009). Strategic model of LNG arbitrage: Analysis of LNG trade in Atlantic Basin. In 32nd International Association for Energy Economics Conference Proceedings.

Iwata, M. (2012, December 5,). Chevron: Most LNG prices to remain linked to oil. The Wall Street Journal. http://www.wsj . com/articles/SB10001424127887324640104578160712548841932.

Jensen, J. T. (2011). Asian natural gas markets supply infrastructure and pricing issues. Technical report, Pacific Energy Summit Conference Paper.

Johansen, S. (1988). Statistical analysis of cointegration vectors. Journal of Economic Dynamics and Control 12(2), 231-254.

Kejriwal, M. (2008). Cointegration with structural breaks: An application to the Feldstein-Horioka puzzle. Studies in Nonlinear Dynamics \& Econometrics 12(1), 1-39.

Kejriwal, M. and P. Perron (2008a). Data dependent rules for selection of the number of leads and lags in the Dynamic OLS cointegrating regression. Econometric Theory 24(5), 1425.

Kejriwal, M. and P. Perron (2008b). The limit distribution of the estimates in cointegrated regression models with multiple structural changes. Journal of Econometrics 146(1), 59-73.

Kejriwal, M. and P. Perron (2010). Testing for multiple structural changes in cointegrated regression models. Journal of Business \& Economic Statistics 28(4), 503-522.

Li, R., R. Joyeux, and R. D. Ripple (2014). International natural gas market integration. The Energy Journal 35(4), 159-179.

Liu, J., S. Wu, and J. V. Zidek (1997). On segmented multivariate regression. Statistica Sinica 7(2), $497-525$.

MacKinnon, J. G. (2010). Critical values for cointegration tests. Technical report, Queen's Economics Department Working Paper.

Medlock, III, K. B. (2014). Natural gas price in Asia: What to expect and what it means. Policy report, The James A. Baker III Institute for Public Policy, Rice University.

Mitrova, T. (2014). The geopolitics of Russian natural gas. Technical report, The James A. Baker III Institute for Public Policy, Rice University. 
Miyamoto, A. (2008). Natural gas in Japan. In J. Stern (Ed.), Natural Gas in Asia: The Challenges of Growth in China, India, Japan and Korea, pp. 116-173. Oxford University Press.

Miyamoto, A., C. Ishiguro, and T. Yamada (2009). Irrational LNG pricing impedes development of Asian natural gas markets: A perspective on market value. 24th World Gas Conference, Buenos Aires, Argentina.

Neumann, A. and A. Cullmann (2012). What's the story with natural gas markets in Europe? Empirical evidence from spot trade data. In 2012 9th International Conference on the European Energy Market (EEM), pp. 1-6. IEEE.

Neumann, A., B. Siliverstovs, and C. v. Hirschhausen (2006). Convergence of European spot market prices for natural gas? A real-time analysis of market integration using the Kalman filter. Applied Economics Letters 13(11), 727-732.

Noguera, J. (2013). Oil prices: Breaks and trends. Energy Economics 37, 60-67.

Osterwald-Lenum, M. (1992). A note with quantiles of the asymptotic distribution of the maximum likelihood cointegration rank test statistics. Oxford bulletin of economics and statistics $54(3)$, 461-472.

Perron, P. (1989). The great crash, the oil price shock, and the unit root hypothesis. Econometrica 57(6), 1361-1401.

Ramberg, D. J. and J. Parsons (2012). The weak tie between natural gas and oil prices. The Energy Journal 33(2), 13-35.

Saikkonen, P. (1991). Asymptotically efficient estimation of cointegration regressions. Econometric Theory 7(1), 1-21.

Siliverstovs, B., G. L'Hégaret, A. Neumann, and C. von Hirschhausen (2005). International market integration for natural gas? A cointegration analysis of prices in Europe, North America and Japan. Energy Economics 27(4), 603-615.

Stock, J. H. and M. W. Watson (1993). A simple estimator of cointegrating vectors in higher order integrated systems. Econometrica 61(4), 783-820.

True, W. R. (2013). LNG update: Global LNG pricing evolves; supply, demand struggle toward balance. Oil \& Gas Journal Online 111(4).

Villar, J. A. and F. L. Joutz (2006). The relationship between crude oil and natural gas prices. Energy Information Administration, Office of Oil and Gas, 1-43.

Weems, P. R. (2006). Evolution of long-term LNG sales contracts: Trends and issues. Oil, Gas $\&$ Energy Law Intelligence $4(1)$. 
White, B. (2014). LNG buyers continue to seek price relief. Pipeline ES Gas Journal 241(8), 68-70.

Zivot, E. and D. Andrews (1992). Further evidence on the great crash, the oil-price shock, and the unit-root. Journal of Business 8 Economic Statistics 10(0), 3. 